\title{
UK Renal Registry 19th Annual Report: Chapter 13 Home Therapies in 2015: National and Centre-specific Analyses
}

\author{
Matthew Tabinor ${ }^{a}$, Anna Casula ${ }^{b}$, Martin Wilkie ${ }^{c}$, Simon Davies ${ }^{a}$, Fergus Caskey ${ }^{\text {bde }}$, \\ Mark Lambie ${ }^{a}$ \\ a University Hospital of North Midlands, Stoke-on-Trent, UK; ${ }^{b}$ UK Renal Registry, Bristol, UK;

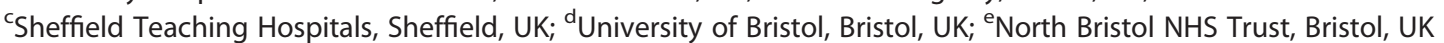

\begin{abstract}
Keywords
Comorbidity - Deprivation - Dialysis - End stage renal disease Established renal failure - Ethnicity - Haemodialysis - Home haemodialysis . Home therapies · Incidence · Peritoneal dialysis · Prevalence · Renal replacement therapy - Technique failure $\cdot$ Transplantation $\cdot$ Treatment modality
\end{abstract}

\section{Summary}

- The use of peritoneal dialysis (PD) has continued to fall, down to $5.9 \%$ of all renal replacement therapy (RRT) patients in 2015 compared to $7.2 \%$ in 2011, whilst home haemodialysis (HHD) is slightly more common at $2.0 \%$ in 2015 compared to $1.7 \%$ in 2011.

- There was significant variability between centres in the use of home dialysis: the probability of starting $\mathrm{PD}$ within the first year ranged from $6.3 \%$ to $49.7 \%$, whilst the probability of starting $\mathrm{HHD}$ in the first year ranged from $0.02 \%$ to $6.6 \%$.

- The median age differed substantially between modalities, with prevalent HHD patients the youngest (55 years), PD intermediate (64 years) and in-centre haemodialysis (ICHD) the oldest (68 years).

- Home dialysis was used less by ethnic minorities, with non-Whites making up $28 \%$ of prevalent ICHD, $22 \%$ of PD and $13 \%$ of HHD.
- The proportion of prevalent patients on each dialysis modality differed by level of social deprivation, with $16.3 \%$ and $9.8 \%$ of the least and most deprived quintiles of deprivation using $\mathrm{PD}$, respectively. The difference for HHD is less marked (5.6\% and $4.6 \%$ for the same quintiles).

- Prevalent HHD patients had the lowest comorbidity burden (66\% with no comorbidity), PD patients had an intermediate burden (61\% with no comorbidity) and ICHD had the highest burden (52\% with no comorbidity).

- HHD patients were more likely to have had a previous transplant (40.3\% vs $7.2 \%)$. More than a third of HHD patients (36.8\%) had previously received $\mathrm{PD}$, whilst only a quarter of $\mathrm{PD}$ patients (24.3\%) had previously received any form of haemodialysis (HD).

- Current absolute levels of both PD and HHD were negatively associated with transplantation levels, but only changes in PD were negatively associated with changes in transplantation levels.

- There was significant variability between centres in PD outcomes, with the probability of switching to $\mathrm{HD}$ within one year of starting PD ranging from $0.0 \%$ to $31.6 \%$.

\begin{tabular}{ll}
\hline KARGER & $\begin{array}{l}\text { C } 2017 \text { The UK Renal Registry } \\
\text { Published by S. Karger AG, Basel Karger }\end{array}$ \\
Fax +4161306 1234 & Eencess \\
E-Mail karger@karger.com & $\begin{array}{l}\text { This article is licensed under the Creative Commons Attribution- } \\
\text { www.karger.com/nef }\end{array}$ \\
$\begin{array}{l}\text { NonCommercial-NoDerivatives 4.0 International License (CC BY- } \\
\text { NC-ND) (http://www.karger.com/Services/OpenAccessLicense). } \\
\text { Usage and distribution for commercial purposes as well as any } \\
\text { distribution of modified material requires written permission. }\end{array}$
\end{tabular}

Matthew Tabinor

UK Renal Registry, Southmead Hospital, Southmead Road,

Bristol, BS10 5NB, UK

Email: renalregistry@renalregistry.nhs.uk 


\section{Introduction}

Previous UK Renal Registry (UKRR) annual reports have described country and centre-specific rates for home therapies (HTs), home haemodialysis (HHD) and peritoneal dialysis (PD), within the incidence and prevalence chapters. Although the use of HTs has changed significantly over time, until now they have not been the focus of a chapter. Furthermore, there has not been an assessment of whether the differences in prevalence of HT use are significant, and aside from mortality as an outcome, there has not been an assessment of differences in outcome by centre.

This chapter describes the home dialysis patient population compared with the in-centre haemodialysis (ICHD) population. It describes the variability in use of HTs and outcomes between countries and centres and begins to explore the factors that may drive some of this variability.

\section{Methods}

\section{Prevalence of home therapies}

Prevalent patients are defined as all patients over 18 years old, alive and receiving renal replacement therapy (RRT) on 31st December 2015 at a UK adult renal centre. Data from Scottish centres were obtained from the Scottish Renal Registry. Data from Welsh, Northern Irish and English centres were collected by the UKRR. Cambridge renal centre (Addenbrooke's) was unable to submit the 2015 data at patient level by the closing date of the 2015 database and was therefore excluded from all analyses on prevalent 2015 RRT patients.

Home therapies refer to $\mathrm{PD}$, including continuous ambulatory PD (CAPD) and automated PD (APD), and HHD. Analyses are presented for all HT patients, or separately for PD and HHD patients, compared to ICHD patients. When looking at prevalence of HTs and changes over time, prevalence of transplantation is also presented for comparison, because changes in one modality may affect the use of another. Prevalent cohorts from 2011-2015 were analysed to compare changes in use of different treatments over time or correlation between initial prevalence of HT and its change with time (Pearson correlation coefficients are given).

The default method for allocating patients to centres was based on the centre sending quarterly data. Recognising the role of secondary care renal services in ensuring access to HHD and transplantation where these are not available locally, HHD and transplanted patients, and PD patients living in the area covered by Colchester (which does not offer a PD programme) were allocated to centres according to postcode of residence (see appendix E: Methodology for Estimating Catchment Populations of Renal Centres in the UK for Dialysis Patients). Where this was done, it has been specified in the relevant result.
Characteristics of patients on home therapies

Age, gender, primary renal disease (PRD), ethnic origin and level of social deprivation were examined for prevalent dialysis patients, by treatment modality (see appendix H: Coding www. renalreg.org). For the purpose of this analysis, patients were grouped into White, South Asian, Black, Other and Unknown. Social deprivation is expressed as quintiles of the index of multiple deprivation (IMD) for England (https://www.gov.uk/government/ statistics/english-indices-of-deprivation-2015), Northern Ireland (https://www.nisra.gov.uk/publications/nothern-ireland-multipledeprivation-measure-2010-soa-results), Scotland (http://www. gov.scot/Topics/Statistics/SIMD) and Wales (http://gov.wales/ statistics-and-research/welsh-index-multiple-deprivation/?lang= en). For both HHD and PD prevalent patients, time on a HT was defined as the time a patient had been consecutively on a HT up to 31st December 2015, ignoring changes to another dialysis modality lasting fewer than 30 days.

Differences in demographic characteristics between treatment groups in the UK dialysis population were tested using the Chisquared and Kruskal-Wallis tests for categorical and continuous variables, respectively. Likelihood ratio tests were used to test for the presence of interactions between demographic factors such as age and gender in multivariable logistic regression models where the outcome was the use of HTs. For centre-level analyses, logistic regression models were used to estimate if the proportion of ethnic minority dialysis patients on HTs differed from the expected proportion (based on each centre's dialysis population). The percentages of PD (or HHD) patients from ethnic minorities versus the percentage of ICHD from ethnic minorities, at centre level, are presented in the form of scatterplots. Where there was evidence of significant differences, centres with a minimum of five ethnic minority patients on HHD or PD were highlighted in figures as outliers. These analyses were conducted using SAS 9.3.

\section{Competing risk analyses}

Cumulative incidence competing risk (CICR) methodology was used to analyse time to HT uptake and time to PD treatment failure rather than using Kaplan-Meier survival analysis. This approach was adopted because an important assumption of Kaplan-Meier analysis is that subjects experiencing censored observations should have, at any time, the same survival probability as those who continue to be followed until the event of interest or the end of study [1]. This means that, for example, censoring at death when looking at PD uptake would translate into assuming that patients who died had a similar chance to start PD as those still at risk (alive and on HD), which is usually not the case and therefore results from a Kaplan-Meier analysis would be biased. Therefore, the CICR methodology has been adopted and considered both transplantation and death as competing events in the survival analyses described below and from these analyses derived unbiased estimates of the cumulative incidence for the event of interest and competing events.

HT uptake To estimate the uptake of HTs in the UK, a cohort of incident patients starting RRT between 2011 and 2014 was identified. Adult patients were followed from their first day of RRT until 31st December 2015, with the event of interest being start of PD or start of HHD. The competing risks in these analyses were transplantation and death on ICHD. Patients were censored when they recovered renal function, stopped treatment without 
recovery, were lost to follow-up or ended follow-up without having had the event. Separate analyses were conducted with censoring at transplantation to allow comparisons with international data from the ANZDATA report [2]. As the UKRR did not receive patient level data from Cambridge, patients starting RRT in this centre were followed-up until 31st December 2014 and those starting RRT during 2014 were excluded from analyses to allow a minimum potential follow-up of one year. Results from these analyses are presented as unadjusted cumulative incidence curves for the uptake of HHD and PD up to two years from RRT start and are shown by country, whilst the unadjusted one-year cumulative incidence of PD and HHD uptake, with confidence intervals (CIs), are shown by centre.

PD technique failure The 2007-2014 incident PD cohort was analysed to investigate PD technique failure. The cohort included only patients starting RRT on PD at day zero and remaining on $\mathrm{PD}$ for a minimum of 90 days. $\mathrm{PD}$ technique survival from day 90 until 31st December 2015 onwards was then analysed using CICR methodology. Cambridge patients were followed-up only to 31st December 2014 and those starting PD in 2014 were excluded from analyses. The event of interest was PD technique failure, defined as a change to haemodialysis (HD) lasting more than 30 days. Transplantation and death on PD were considered as competing risks and censoring was applied at recovery of function, end of treatment without recovery, loss to follow-up or end of follow-up. Results were presented as unadjusted cumulative incidence curves for PD technique failure up to five years from 90 days after PD start. The cumulative incidence curves of the two competing events (transplantation and death on PD) are shown by country, whilst the unadjusted one-year cumulative incidence of $\mathrm{PD}$ technique failure, with CIs, are shown by centre.

All competing risks analyses were performed using Stata 12.

\section{Results}

\section{Prevalence of home therapies in the UK}

$U K$ - and country-level home therapy use and changes over time

At the end of 2015, there were 59,567 adults receiving RRT in the UK. Of these, 27,912 (46.9\%) were on some form of dialysis. The prevalence rates for RRT overall and the individual dialysis modalities in 2015 are shown in table 13.1 .

Expressed as a percentage of the prevalent UK dialysis population, $16.9 \%$ of patients were on a HT, with $4.2 \%$ on HHD and $12.7 \%$ on PD $(5.4 \%$ on CAPD and $7.3 \%$ on APD).

HHD was used less frequently than PD and this pattern was consistent across the individual countries. Patients using HHD constituted $6.7 \%$ of all dialysis patients in Wales $(30.2 \%$ of all HT), compared with 4.2\%, 2.6\% and 2.9\% of all dialysis in England, Scotland and Northern Ireland, respectively $(25.0 \%, 20.1 \%$ and $19.2 \%$ of all HT, respectively).

The coding for sub-types of PD modality has not been extensively validated, so some caution is warranted in interpreting these data. This is likely to be a particular issue for assisted PD. That accepted, APD appeared to be more commonly used than CAPD, and the difference was particularly marked in Northern Ireland.

In an analysis stratified according to country and age group (figure 13.1), HT use followed a similar pattern

Table 13.1. Prevalence of dialysis in the UK, by country ${ }^{\mathrm{a}}$, on 31 st December 2015

\begin{tabular}{|c|c|c|c|c|c|}
\hline & England $^{c}$ & $\mathrm{~N}$ Ireland & Scotland & Wales & $\mathrm{UK}^{\mathrm{c}}$ \\
\hline Number of prevalent patients on RRT & 49,972 & 1,679 & 4,828 & 3,088 & 59,567 \\
\hline Number of prevalent patients on dialysis & 23,695 & 696 & 2,138 & 1,383 & 27,912 \\
\hline Prevalence rate dialysis (pmp) $(\mathrm{HT}+$ in-centre $)$ & 432 & 376 & 398 & 446 & 429 \\
\hline Prevalence rate HHD (pmp) & 18 & 11 & 10 & 30 & 18 \\
\hline Prevalence rate $\mathrm{PD}(\mathrm{pmp})$ & 55 & 45 & 41 & 69 & 54 \\
\hline Prevalence rate APD (pmp) & 31 & 43 & 27 & 36 & 31 \\
\hline Prevalence rate HT (pmp) & 74 & 56 & 51 & 99 & 72 \\
\hline $95 \% \mathrm{CI}$ of the prevalence rate $\mathrm{HT}$ (pmp) & $71-76$ & $45-67$ & $45-57$ & $88-110$ & $70-75$ \\
\hline
\end{tabular}

RRT - renal replacement therapy; pmp - per million population; HT - home therapy; HHD - home haemodialysis; PD - peritoneal dialysis; CAPD - continuous ambulatory PD; APD - automated PD; CI - confidence interval

${ }^{\mathrm{a}}$ Based on postcode of residency

${ }^{b}$ Data from the Office of National Statistics, National Records of Scotland and the Northern Ireland Statistics and Research Agency - based on the 2011 census

${ }^{\mathrm{c}}$ Prevalent numbers do not include Cambridge patients 


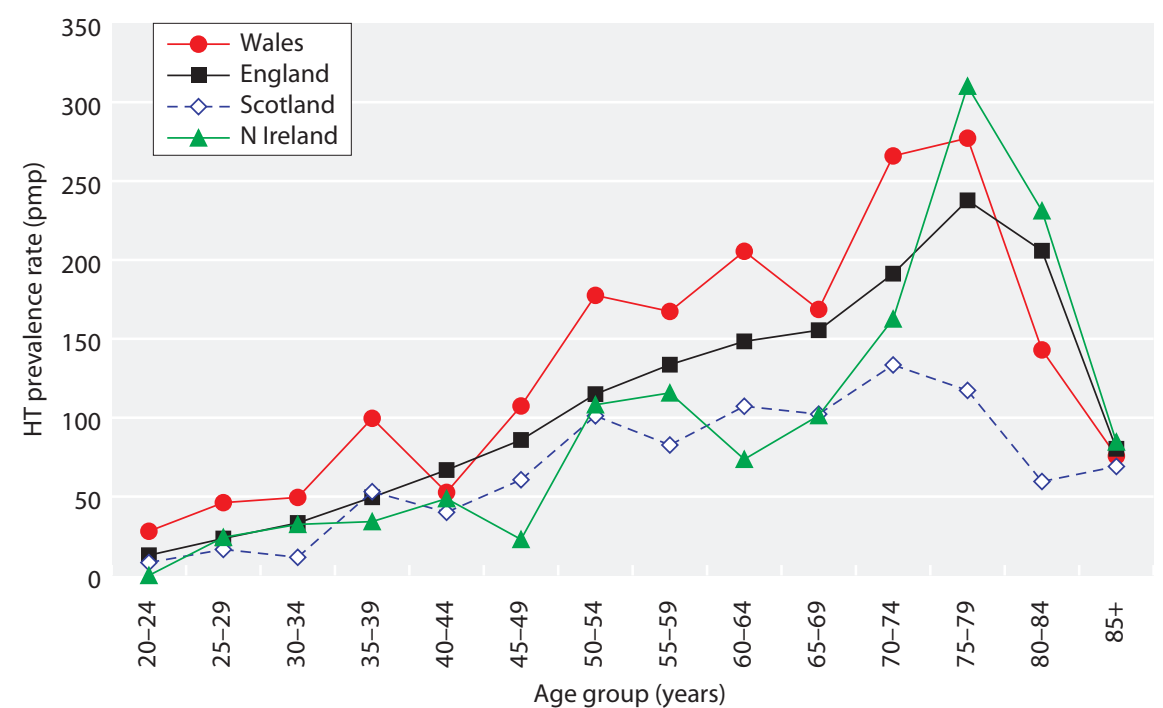

Fig. 13.1. Prevalence rate of HTs, per million population by age group and country*, on 31st December 2015

*Based on postcode of residency to that seen for the dialysis population as a whole, with prevalence increasing with age (data not shown).

The overall use of HTs in the total UK RRT population fell by 1.0\% between 2011-2015 (appendix 1, table 13.7). This fall was driven by the change in PD use $(-1.2 \%)$ over this time, with HHD growing by $0.3 \%$. Roughly the same pattern was evident throughout the countries, although Scotland and Northern Ireland both experienced a small fall in HHD use $(-0.2 \%$ and $-0.8 \%$ respectively). As changes in one modality may affect the use of another (e.g. transplantation rates may affect
PD use), data on all the modalities are presented. Transplantation grew significantly over this time period, but the UK change of $3.6 \%$ masks differences between the countries: numbers of transplants in Wales grew by $2.9 \%$, in England by $3.3 \%$, in Scotland by $4.9 \%$ and in Northern Ireland by $11.5 \%$.

Centre-level home therapy use and changes over time

The breakdown of modality use in prevalent dialysis patients between centres is shown in table 13.2. Data from this table are also displayed, ordered by increasing

Table 13.2. Proportion of prevalent RRT patients using HTs, ICHD and transplantation, by country and centre*, on 31 st December 2015

\begin{tabular}{|c|c|c|c|c|c|c|}
\hline \multirow[b]{2}{*}{ Centre } & \multirow{2}{*}{$\begin{array}{c}\text { RRT patients } \\
N\end{array}$} & \multicolumn{4}{|c|}{$\%$ of prevalent RRT patients } & \multirow{2}{*}{$\begin{array}{c}\text { Ratio } \\
\text { HT/dialysis }\end{array}$} \\
\hline & & HT & ICHD & $\mathrm{Tx}$ & $\mathrm{HT}+\mathrm{Tx}$ & \\
\hline \multicolumn{7}{|l|}{ England } \\
\hline B Heart & 822 & 7.8 & 49.5 & 42.7 & 50.5 & 0.14 \\
\hline B QEH & 1,917 & 9.6 & 49.9 & 40.5 & 50.1 & 0.16 \\
\hline Basldn & 358 & 10.3 & 45.3 & 44.4 & 54.7 & 0.19 \\
\hline Bradfd & 628 & 4.3 & 36.0 & 59.7 & 64.0 & 0.11 \\
\hline Brightn & 1,077 & 10.7 & 36.1 & 53.2 & 63.9 & 0.23 \\
\hline Bristol & 1,341 & 5.5 & 37.5 & 57.0 & 62.5 & 0.13 \\
\hline Carlis & 280 & 13.6 & 28.9 & 57.5 & 71.1 & 0.32 \\
\hline Carsh & 1,788 & 8.2 & 44.0 & 47.9 & 56.0 & 0.16 \\
\hline Chelms & 348 & 7.8 & 41.4 & 50.9 & 58.6 & 0.16 \\
\hline Colchr & 226 & 4.4 & 53.1 & 42.5 & 46.9 & 0.08 \\
\hline Covnt & 899 & 11.2 & 37.6 & 51.2 & 62.4 & 0.23 \\
\hline Derby & 627 & 17.9 & 33.2 & 49.0 & 66.8 & 0.35 \\
\hline Donc & 396 & 9.6 & 43.2 & 47.2 & 56.8 & 0.18 \\
\hline Dorset & 738 & 7.3 & 38.1 & 54.6 & 61.9 & 0.16 \\
\hline Dudley & 379 & 19.8 & 42.0 & 38.3 & 58.0 & 0.32 \\
\hline Exeter & 1,049 & 8.2 & 41.0 & 50.8 & 59.0 & 0.17 \\
\hline
\end{tabular}


Table 13.2. Continued

\begin{tabular}{|c|c|c|c|c|c|c|}
\hline \multirow[b]{2}{*}{ Centre } & \multirow{2}{*}{$\begin{array}{c}\text { RRT patients } \\
\qquad N\end{array}$} & \multicolumn{4}{|c|}{$\%$ of prevalent RRT patients } & \multirow{2}{*}{$\begin{array}{c}\text { Ratio } \\
\text { HT/dialysis }\end{array}$} \\
\hline & & HT & ICHD & $\mathrm{Tx}$ & $\mathrm{HT}+\mathrm{Tx}$ & \\
\hline Hull & 931 & 9.3 & 37.6 & 53.1 & 62.4 & 0.20 \\
\hline Ipswi & 345 & 8.7 & 41.4 & 49.9 & 58.6 & 0.17 \\
\hline Kent & 1,135 & 7.0 & 35.9 & 57.1 & 64.1 & 0.16 \\
\hline L Kings & 1,321 & 8.3 & 41.9 & 49.7 & 58.1 & 0.17 \\
\hline L Rfree & 1,837 & 9.6 & 37.7 & 52.7 & 62.3 & 0.20 \\
\hline L St.G & 808 & 6.9 & 41.3 & 51.7 & 58.7 & 0.14 \\
\hline L West & 3,114 & 2.9 & 45.8 & 51.3 & 54.2 & 0.06 \\
\hline Leeds & 1,453 & 5.4 & 33.7 & 61.0 & 66.3 & 0.14 \\
\hline Middlbr & 911 & 4.2 & 37.1 & 58.7 & 62.9 & 0.10 \\
\hline Newc & 952 & 7.1 & 30.6 & 62.3 & 69.4 & 0.19 \\
\hline Norwch & 740 & 8.4 & 42.3 & 49.3 & 57.7 & 0.17 \\
\hline Nottm & 1,012 & 11.4 & 35.5 & 53.2 & 64.5 & 0.24 \\
\hline Oxford & 1,485 & 7.3 & 28.3 & 64.4 & 71.7 & 0.21 \\
\hline Plymth & 474 & 8.9 & 27.4 & 63.7 & 72.6 & 0.24 \\
\hline Ports & 1,691 & 7.4 & 36.1 & 56.5 & 63.9 & 0.17 \\
\hline Prestn & 1,354 & 6.9 & 39.4 & 53.7 & 60.6 & 0.15 \\
\hline Redng & 937 & 8.1 & 31.7 & 60.2 & 68.3 & 0.20 \\
\hline Salford & 1,278 & 8.2 & 30.0 & 61.8 & 70.0 & 0.22 \\
\hline Sheff & 1,235 & 7.9 & 40.3 & 51.7 & 59.7 & 0.16 \\
\hline York & 475 & 8.2 & 31.4 & 60.4 & 68.6 & 0.21 \\
\hline \multicolumn{7}{|c|}{ Northern Ireland } \\
\hline Antrim & 276 & 8.7 & 43.1 & 48.2 & 56.9 & 0.17 \\
\hline Belfast & 589 & 5.1 & 29.5 & 65.4 & 70.5 & 0.15 \\
\hline Newry & 245 & 10.2 & 32.7 & 57.1 & 67.3 & 0.24 \\
\hline Ulster & 247 & 3.6 & 42.5 & 53.8 & 57.5 & 0.08 \\
\hline West NI & 324 & 4.9 & 35.5 & 59.6 & 64.5 & 0.12 \\
\hline \multicolumn{7}{|l|}{ Scotland } \\
\hline Abrdn & 525 & 5.9 & 40.6 & 53.5 & 59.4 & 0.13 \\
\hline Airdrie & 511 & 3.7 & 38.2 & 58.1 & 61.8 & 0.09 \\
\hline D \& Gall & 137 & 10.2 & 37.2 & 52.6 & 62.8 & 0.22 \\
\hline Dundee & 426 & 4.5 & 43.4 & 52.1 & 56.6 & 0.09 \\
\hline Edinb & 740 & 4.6 & 37.6 & 57.8 & 62.4 & 0.11 \\
\hline Glasgw & 1,580 & 4.9 & 36.6 & 58.5 & 63.4 & 0.12 \\
\hline Inverns & 254 & 6.7 & 35.4 & 57.9 & 64.6 & 0.16 \\
\hline Klmarnk & 355 & 13.0 & 35.5 & 51.5 & 64.5 & 0.27 \\
\hline Krkcldy & 306 & 6.5 & 49.0 & 44.4 & 51.0 & 0.12 \\
\hline
\end{tabular}


Table 13.2. Continued

\begin{tabular}{|c|c|c|c|c|c|c|}
\hline \multirow[b]{2}{*}{ Centre } & \multirow{2}{*}{$\begin{array}{c}\text { RRT patients } \\
N\end{array}$} & \multicolumn{4}{|c|}{$\%$ of prevalent RRT patients } & \multirow{2}{*}{$\begin{array}{c}\text { Ratio } \\
\text { HT/dialysi }\end{array}$} \\
\hline & & HT & ICHD & $\mathrm{Tx}$ & $\mathrm{HT}+\mathrm{Tx}$ & \\
\hline \multicolumn{7}{|l|}{ Wales } \\
\hline Bangor & 189 & 17.5 & 36.5 & 46.0 & 63.5 & 0.32 \\
\hline Cardff & 1,481 & 7.2 & 31.7 & 61.2 & 68.3 & 0.18 \\
\hline Clwyd & 185 & 13.0 & 41.6 & 45.4 & 58.4 & 0.24 \\
\hline Swanse & 888 & 11.0 & 37.0 & 51.9 & 63.0 & 0.23 \\
\hline Wrexm & 289 & 14.2 & 37.0 & 48.8 & 63.0 & 0.28 \\
\hline England & 49,974 & 8.1 & 39.4 & 52.5 & 60.6 & 0.17 \\
\hline $\mathbf{N}$ Ireland & 1,681 & 6.2 & 35.3 & 58.5 & 64.7 & 0.15 \\
\hline Scotland & 4,834 & 5.7 & 38.6 & 55.6 & 61.4 & 0.13 \\
\hline Wales & 3,032 & 10.0 & 34.7 & 55.4 & 65.3 & 0.22 \\
\hline UK & 59,521 & 7.9 & 39.0 & 53.1 & 61.0 & 0.17 \\
\hline
\end{tabular}

RRT - renal replacement therapy; HT - home therapy; ICHD - in-centre haemodialysis; Tx - transplant

*Based on postcode of residency

rate of combined transplant/HT use (figure 13.2). Across the whole of the UK, 7.9\% of the RRT population were using a HT, but rates between centres varied widely from $2.9 \%$ to $19.8 \%$. Rates for combined transplant/HT use also varied widely between centres, from $46.9 \%$ to $72.7 \%$. Due to this variability, incidence rates for HTs between centres, and their relationship with transplant rates, are explored later in this chapter.

As numerous centres have specifically sought to increase $\mathrm{HHD}$ and/or PD, the change in use of these modalities over the last five years is displayed in appendix 1, table 13.7. There is an association between the level of PD use and the change in that level over time, with higher baseline (2011) levels of PD use being more likely to be associated with a fall in PD use over time - there is a correlation of -0.53 between the proportion of RRT patients on PD in 2011 and the change in the proportion of RRT patients on PD from 20112015. Despite the overall fall, some centres have managed to increase PD use (e.g. Clwyd, Wrexham, Liverpool Aintree and Carlisle). However, these centres started with low to medium levels of PD use in 2011.

The changes in HHD use range from a fall of $2.1 \%$ to an increase of $3.3 \%$ from 2011-2015. There is no

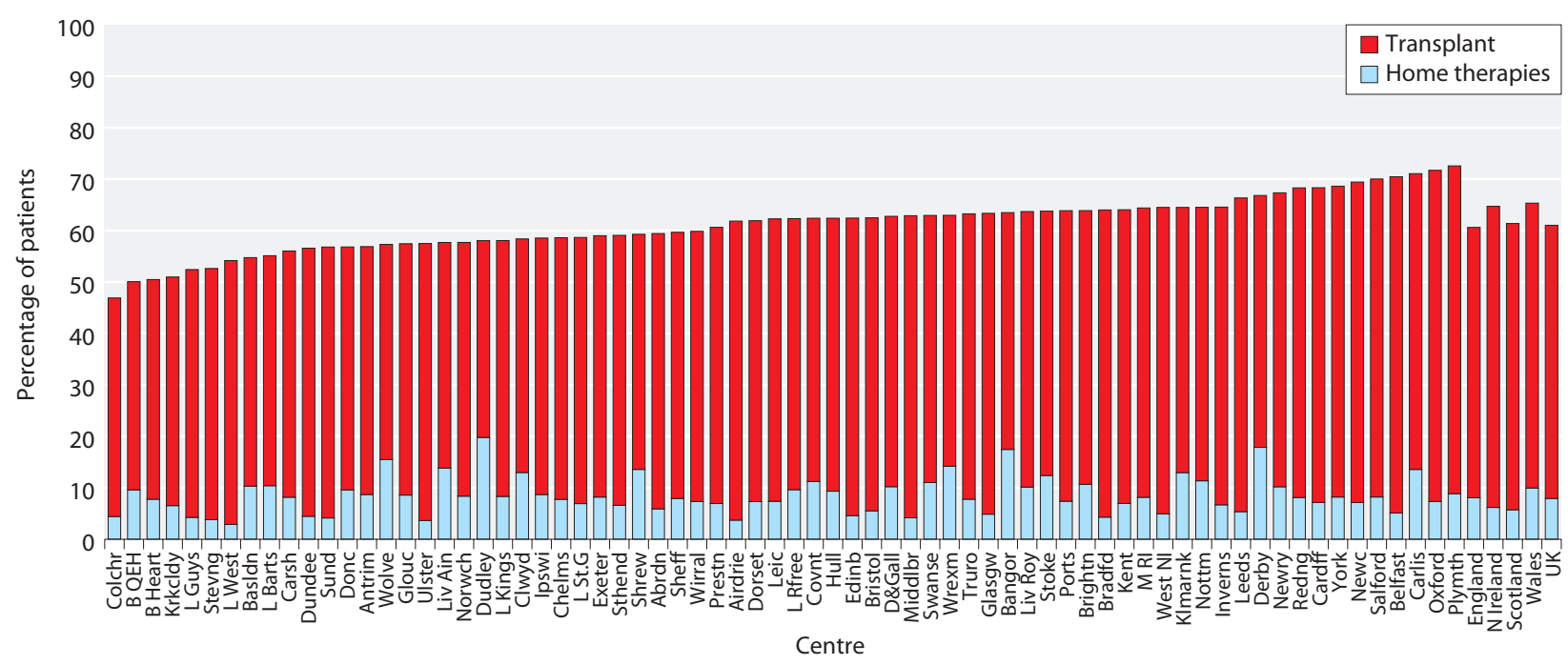

Fig. 13.2. Centre specific proportion of prevalent RRT patients* using a HT or transplantation on 31 st December 2015 * Based on postcode of residency 
apparent association between the 2011 HHD use and the subsequent change, but the overall HHD use rate was much lower than for PD.

It has also been suggested that levels of transplantation may affect rates of HTs and this is borne out in simple correlations. Levels of PD use in 2011 correlate negatively with levels of transplantation in $2011(\mathrm{r}=-0.35)$ and five-year changes in PD use correlate negatively with five-year changes in transplantation $(r=-0.44)$. Levels of HHD use in 2011 also correlate negatively with levels of transplantation in $2011(\mathrm{r}=-0.42)$, but there was no significant association between changes in HHD and transplantation during the five-year follow up $(\mathrm{r}=-0.02)$. It is not clear to what extent these correlations with transplantation reflect a lower probability of starting home dialysis, or a higher probability of stopping home dialysis due to transplantation.

There was some evidence that quality improvement initiatives can affect HT use. Between 2010 and 2012, the West Midlands introduced a commissioning target to increase HT uptake, with evidence that this led to an increase in HT rates [3]. This can also be seen in the UKRR data. The average rates of HHD and PD in the Midlands grew from $1.6 \%$ and $10.2 \%$ in 2010 , respectively, to $3.3 \%$ and $11.4 \%$ in 2012, respectively. However, this growth appears not to have continued, with the average $\mathrm{HHD}$ and $\mathrm{PD}$ rates stable or slightly reduced in 2015 at $3.4 \%$ and $9.4 \%$, respectively.

Home therapies patient demographics: UK, country and centre-level

Age

The median age of prevalent UK HT patients was 61 years (table 13.3), considerably younger than the ICHD median age of 68 years. As has been noted previously, the HHD population was younger than the PD population, with a median age of 55 and 64 years respectively. Practice patterns such as the use of assisted PD may influence the age of patients using different modalities between centres, so the median age for patients using

Table 13.3. Median age and gender of prevalent dialysis patients, by country and centre, on 31 st December 2015

\begin{tabular}{|c|c|c|c|c|c|c|c|}
\hline \multirow[b]{2}{*}{ Centre } & \multirow{2}{*}{$\begin{array}{c}\text { HT patients } \\
N\end{array}$} & \multicolumn{4}{|c|}{ Median age (years) } & \multicolumn{2}{|c|}{$\%$ male } \\
\hline & & HHD & PD & $\mathrm{HT}$ & ICHD & $\mathrm{HT}$ & ICHD \\
\hline \multicolumn{8}{|l|}{ England } \\
\hline B Heart & 64 & 53 & 67 & 64 & 68 & 62.5 & 60.4 \\
\hline B QEH & 192 & 49 & 60 & 58 & 66 & 61.5 & 57.7 \\
\hline Basldn & 36 & & 58 & 57 & 68 & 58.3 & 64.2 \\
\hline Bradfd & 25 & 49 & 53 & 52 & 63 & 40.0 & 58.0 \\
\hline Brightn & 112 & 58 & 66 & 64 & 69 & 67.9 & 66.6 \\
\hline Bristol & 79 & 58 & 68 & 63 & 70 & 58.2 & 64.4 \\
\hline Carlis & 38 & $\mathrm{n} / \mathrm{a}$ & 70 & 70 & 70 & 63.2 & 69.1 \\
\hline Carsh & 142 & 57 & 66 & 63 & 69 & 54.9 & 63.8 \\
\hline Chelms & 27 & $\mathrm{n} / \mathrm{a}$ & 70 & 70 & 69 & 63.0 & 71.5 \\
\hline Colchr & 0 & & & & 73 & $\mathrm{n} / \mathrm{a}$ & 68.3 \\
\hline Covnt & 102 & 57 & 65 & 63 & 68 & 65.7 & 59.2 \\
\hline Derby & 116 & 63 & 63 & 63 & 68 & 61.2 & 59.1 \\
\hline Donc & 33 & 64 & 69 & 66 & 69 & 72.7 & 58.5 \\
\hline Dorset & 50 & 64 & 73 & 70 & 72 & 62.0 & 63.1 \\
\hline Dudley & 70 & 56 & 61 & 59 & 68 & 51.4 & 67.9 \\
\hline Exeter & 86 & 42 & 68 & 67 & 72 & 61.6 & 65.1 \\
\hline Glouc & 42 & 69 & 67 & 68 & 72 & 52.4 & 65.5 \\
\hline Hull & 84 & 58 & 65 & 62 & 69 & 60.7 & 68.6 \\
\hline Ipswi & 38 & $\mathrm{n} / \mathrm{a}$ & 69 & 69 & 70 & 65.8 & 70.6 \\
\hline Kent & 76 & 54 & 64 & 63 & 70 & 63.2 & 64.0 \\
\hline L Barts & 230 & 50 & 61 & 60 & 62 & 65.7 & 59.5 \\
\hline L Guys & 82 & 52 & 62 & 54 & 62 & 46.3 & 60.3 \\
\hline L Kings & 102 & 54 & 59 & 57 & 64 & 61.8 & 62.1 \\
\hline L Rfree & 175 & 58 & 64 & 63 & 69 & 52.0 & 62.0 \\
\hline L St.G & 53 & 53 & 71 & 70 & 66 & 60.4 & 55.5 \\
\hline L West & 89 & 58 & 65 & 62 & 66 & 53.9 & 60.6 \\
\hline Leeds & 81 & 49 & 53 & 52 & 65 & 56.8 & 59.9 \\
\hline Leic & 168 & 59 & 66 & 61 & 68 & 63.1 & 61.8 \\
\hline
\end{tabular}


Table 13.3. Continued

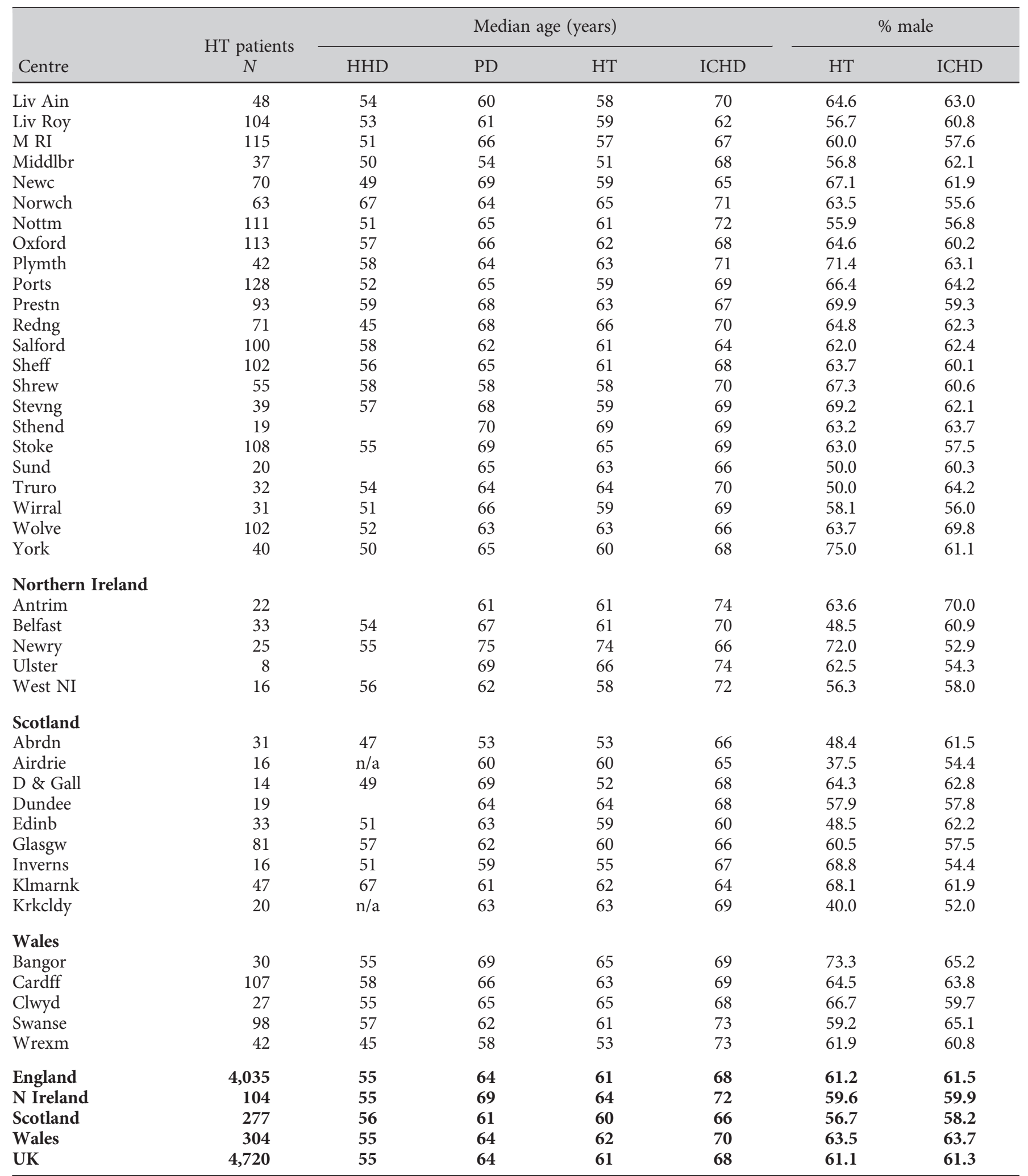

HT - home therapy; HHD - home haemodialysis; PD - peritoneal dialysis; ICHD - in-centre haemodialysis $\mathrm{n} / \mathrm{a}$ - no patients on this treatment; Blank cells - data for only one to two patients 


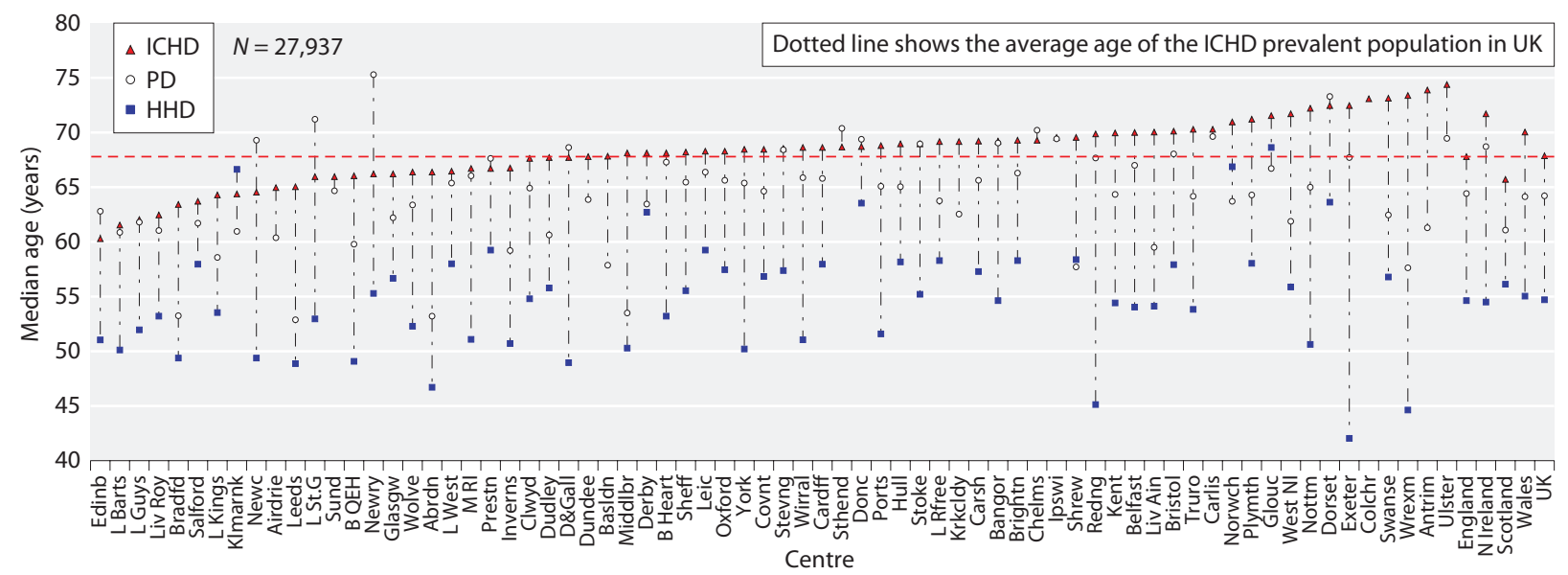

Fig. 13.3. Median age in prevalent dialysis population, by dialysis modality and centre, on 31 st December 2015

each modality is shown by centre in figure 13.3. The same general pattern is evident, with HHD having the youngest population and ICHD having the oldest, but there do appear to be exceptions.

Caution is necessary when interpreting differences in ages between centres, particularly where centres have low numbers of patients on HTs. However, there does appear to be some difference in the median age of PD patients, ranging from 52.9 in Leeds to 75.3 years in Newry. Looking only at centres with larger patient numbers on HTs, Wrexham, Shrewsbury, Leeds and Swansea had PD populations that were markedly younger than their ICHD populations (difference $>10$ years). Conversely, London St. George's and Newcastle were unusual in having PD populations with a median age 5.3 and 4.8 years older than their ICHD populations, respectively.

Differences in the HHD population were less clear due to the smaller patient numbers. Despite this, there do appear to be differences in patient ages between centres, with median ages ranging from 42.0 in Exeter to 68.6 in Gloucester. Looking just at the larger HHD populations, Derby had a median age for HHD of 62.7 years (compared with ICHD 68.1 years), whilst Portsmouth had a median of 51.6 years (compared with ICHD 68.8 years). Together, these differences do raise the possibility that non-patient factors may be having an impact on the age of patients who use HTs.

\section{Gender}

Across the UK, the gender of patients on ICHD and HT modalities was similar, with $61.3 \%$ and $61.1 \%$ of these groups being male respectively (table 13.3). The distribution of HT use according to gender at the individual country level was largely similar, but some large variation was observed by centre with for example, Dudley using HT less than expected in males and Preston using HT more than expected in males (table 13.3).

As shown in figure 13.4, there is a suggestion of an interaction between age and gender in the use of different dialysis modalities. In prevalent dialysis patients, younger

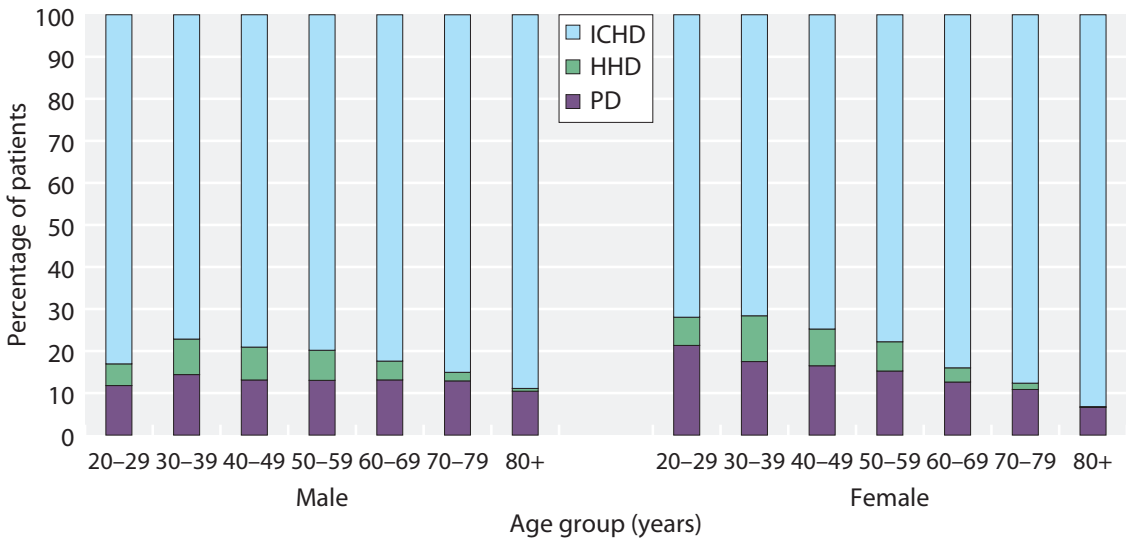

Fig. 13.4. Percentage of prevalent dialysis patients, by age and gender, on 31st December 2015 


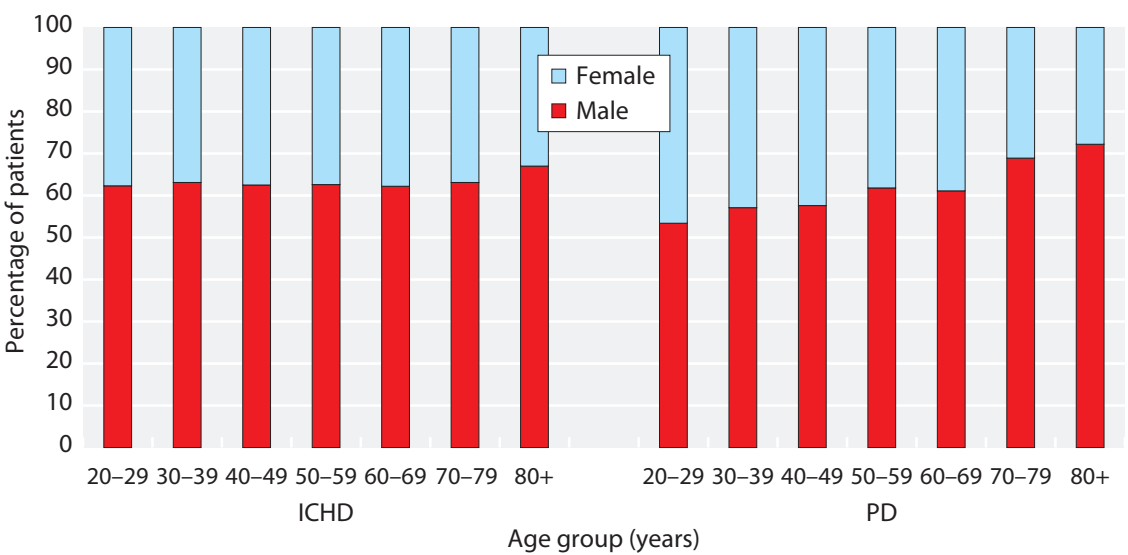

Fig. 13.5. Dialysis modality at start, by age and gender, in the incident ICHD and PD dialysis* cohort, 2011-2015

${ }^{*}$ Patients starting on HHD are excluded because they comprise $<1 \%$ of the cohort $(N=69)$ females appear slightly more likely to use a HT than males, whilst a similar or lower proportion of older females used a HT compared to older males (age-gender interaction $p$-value $<0.001)$. Most of this difference appears to be through differences in PD use. This difference has been further explored in incident patients, using the percentage of patients starting dialysis on either PD or ICHD who are male/female by age (figure 13.5). The same pattern emerged, with females over-represented in the younger age group on PD compared to ICHD, and under-represented in the older PD patients (age-gender interaction $p$-value $<0.0001$ ).

\section{Ethnicity}

A summary of patient ethnicity by centre on 31st December 2015 is presented in table 13.4. There appears to be a systematic difference in the proportion of patients using HTs by ethnicity. For the England, Wales and Northern Ireland ICHD population, $28 \%$ of the patients are from a non-White background, compared to only $13 \%$ of patients using HHD. PD appears to be intermediate between HHD and ICHD with $22 \%$ of patients described as non-White.

This also appears to vary between centres, but at the centre level the proportion of dialysis patients from

Table 13.4. Ethnicity of prevalent dialysis patients, by dialysis modality, country* and centre, on 31 st December 2015

\begin{tabular}{|c|c|c|c|c|c|c|c|c|}
\hline \multirow[b]{2}{*}{ Centre } & \multirow{2}{*}{$\begin{array}{c}\text { HHD patients } \\
\qquad N\end{array}$} & \multicolumn{2}{|c|}{ HHD \% ethnicity } & \multirow{2}{*}{$\begin{array}{c}\text { PD patients } \\
N\end{array}$} & \multicolumn{2}{|c|}{ PD \% ethnicity } & \multicolumn{2}{|c|}{ ICHD \% ethnicity } \\
\hline & & non-White & White & & non-White & White & non-White & White \\
\hline \multicolumn{9}{|l|}{ England } \\
\hline B Heart & 13 & 31 & 69 & 51 & 22 & 78 & 45 & 55 \\
\hline B QEH & 50 & 28 & 72 & 142 & 32 & 68 & 48 & 52 \\
\hline Basldn & & & & 35 & 14 & 86 & 16 & 84 \\
\hline Bristol & 22 & 5 & 95 & 54 & 4 & 96 & 13 & 87 \\
\hline Carlis & 0 & $\mathrm{n} / \mathrm{a}$ & $\mathrm{n} / \mathrm{a}$ & 38 & 0 & 100 & 0 & 100 \\
\hline Carsh & 29 & 14 & 86 & 110 & 24 & 76 & 36 & 64 \\
\hline Chelms & 0 & $\mathrm{n} / \mathrm{a}$ & $\mathrm{n} / \mathrm{a}$ & 23 & 13 & 87 & 9 & 91 \\
\hline Covnt & 16 & 13 & 88 & 86 & 29 & 71 & 25 & 75 \\
\hline Derby & 38 & 18 & 82 & 78 & 14 & 86 & 19 & 81 \\
\hline Glouc & 5 & 0 & 100 & 37 & 11 & 89 & 4 & 96 \\
\hline Hull & 8 & 0 & 100 & 76 & 3 & 97 & 4 & 96 \\
\hline Ipswi & 0 & $\mathrm{n} / \mathrm{a}$ & $\mathrm{n} / \mathrm{a}$ & 35 & 26 & 74 & 13 & 87 \\
\hline Kent & 16 & 6 & 94 & 60 & 7 & 93 & 5 & 95 \\
\hline
\end{tabular}


Table 13.4. Continued

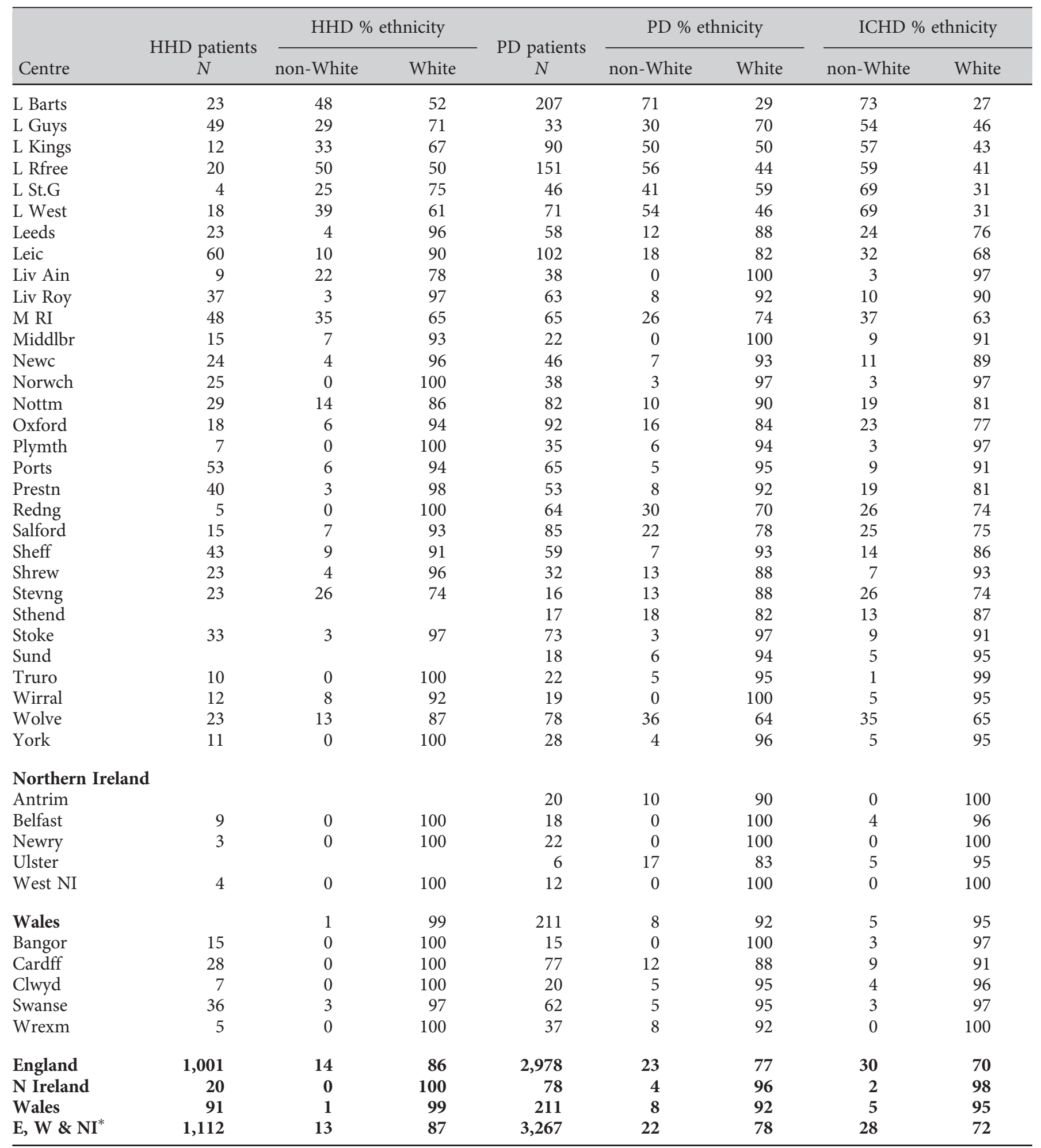

HHD - home haemodialysis; PD - peritoneal dialysis; ICHD - in-centre haemodialysis $\mathrm{n} / \mathrm{a}$ - no patients on this treatment; Blank cells - data for only one to two patients

${ }^{*}$ Scotland not included because of low completeness of ethnicity data 


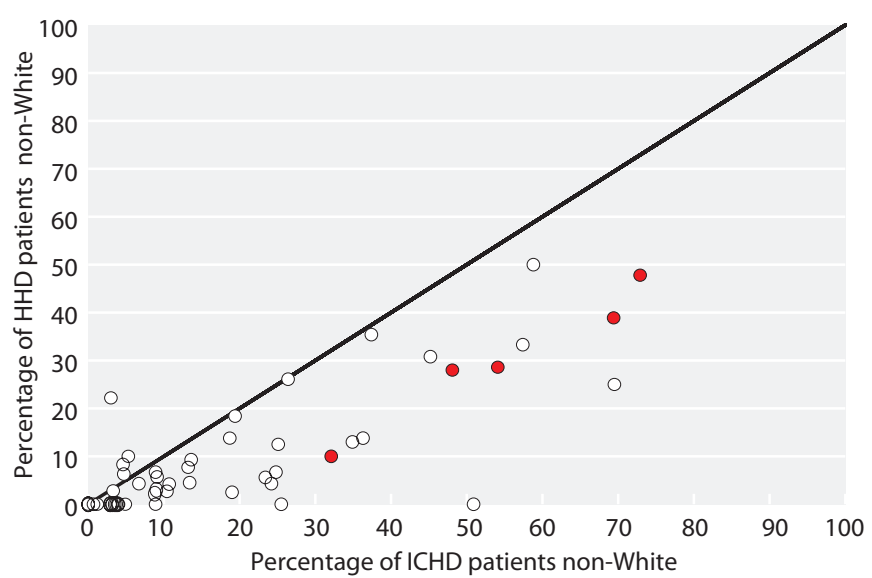

Fig. 13.6A. Percentage of non-White prevalent HHD patients relative to non-White ICHD patients on 31st December 2015

Centres with a lower than expected percentage of ethnic minorities on HHD are highlighted (shown as bold dots) only if they had a minimum of five non-White patients on HHD

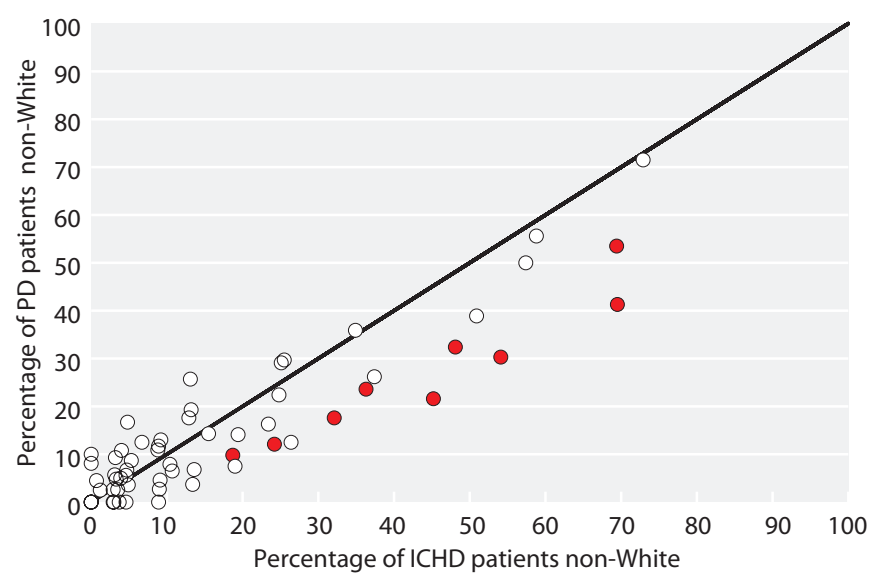

Fig. 13.6B. Percentage of non-White prevalent PD patients relative to non-White ICHD patients on 31st December 2015

Centres with a lower than expected percentage of ethnic minorities on PD are highlighted (shown as bold dots) only if they had a minimum of five non-White patients on PD

ethnic minorities varied widely. The data are therefore presented again in figures $13.6 \mathrm{~A}$ and $\mathrm{B}$ for the HHD and $\mathrm{PD}$ groups respectively, highlighting centres where there were sufficient patients to have reasonable confidence that the differences were not due to chance. This suggests that there may be real differences in access to HTs for patients from non-White ethnic groups, though this is still confounded by other factors such as social deprivation.

\section{Primary renal disease}

The distribution of primary renal disease (PRD) by dialysis modality in prevalent dialysis patients is shown
Table 13.5. PRD in prevalent dialysis patients, by dialysis modality, on 31st December 2015

\begin{tabular}{|c|c|c|c|c|}
\hline PRD & $\%$ HHD & $\% \mathrm{PD}$ & $\%$ ICHD & $\begin{array}{c}\% \text { overall } \\
\text { dialysis }\end{array}$ \\
\hline Aetiology uncertain & 13.7 & 17.0 & 17.0 & 16.8 \\
\hline Diabetes & 12.3 & 22.5 & 25.4 & 24.5 \\
\hline Glomerulonephritis & 26.1 & 16.5 & 14.6 & 15.3 \\
\hline Hypertension & 4.5 & 8.7 & 7.7 & 7.7 \\
\hline Other & 19.8 & 14.7 & 15.7 & 15.7 \\
\hline Polycystic kidney & 9.2 & 7.3 & 6.0 & 6.3 \\
\hline Pyelonephritis & 12.0 & 7.7 & 8.3 & 8.4 \\
\hline Renal vascular disease & 2.4 & 5.5 & 5.4 & 5.3 \\
\hline Missing & 1.8 & 4.7 & 3.9 & 3.9 \\
\hline
\end{tabular}

PRD - primary renal disease; HHD - home haemodialysis; PD peritoneal dialysis; ICHD - in-centre haemodialysis

Excluded centre with $\geqslant 40 \%$ PRD 'aetiology uncertain' (Colchester)

in table 13.5. There is missing PRD data in only $4.6 \%$ of patients. There are statistically significant differences in PRD by modality, particularly for diabetic nephropathy in HHD patients, where only $12.3 \%$ of patients have this $\mathrm{PRD}$, compared to $22.5 \%$ in $\mathrm{PD}$ patients and $25.4 \%$ in ICHD patients. The distribution of PRD causes in ICHD patients more closely reflects PD patients than HHD patients.

\section{Social deprivation}

Previous work has demonstrated that patients who are less socioeconomically deprived are more likely to be on HHD [4], so this finding was retested. Increasing deprivation was still associated with a decreasing proportion of the dialysis population using HTs (figure 13.7, chisquared test $p$-value $<0.001$ for deprivation effect). On 31st December 2015, PD was used by $16.3 \%$ and $9.8 \%$ of prevalent dialysis patients from deprivation quintiles one and five respectively. The difference was less striking for HHD, with $5.0 \%$ and $3.4 \%$ of patients using HHD from quintiles one and five respectively. To look at the effect of social deprivation independent of ethnicity, the same analysis was done within the White population (data not shown). This revealed the same pattern of decreased HT use with increasing deprivation and the same dose-response pattern.

To control for the possibility that informative censoring was affecting the prevalence data, the association between deprivation and HT use was explored in an incident UK dialysis cohort (January 2014-September 2015). The cohort was curtailed in September 2015 to allow modality at day 90 to be determined. At day 90 , the proportion of incident RRT patients on PD was $22.7 \%$ and $16.7 \%$ in the least and most deprived quintiles 


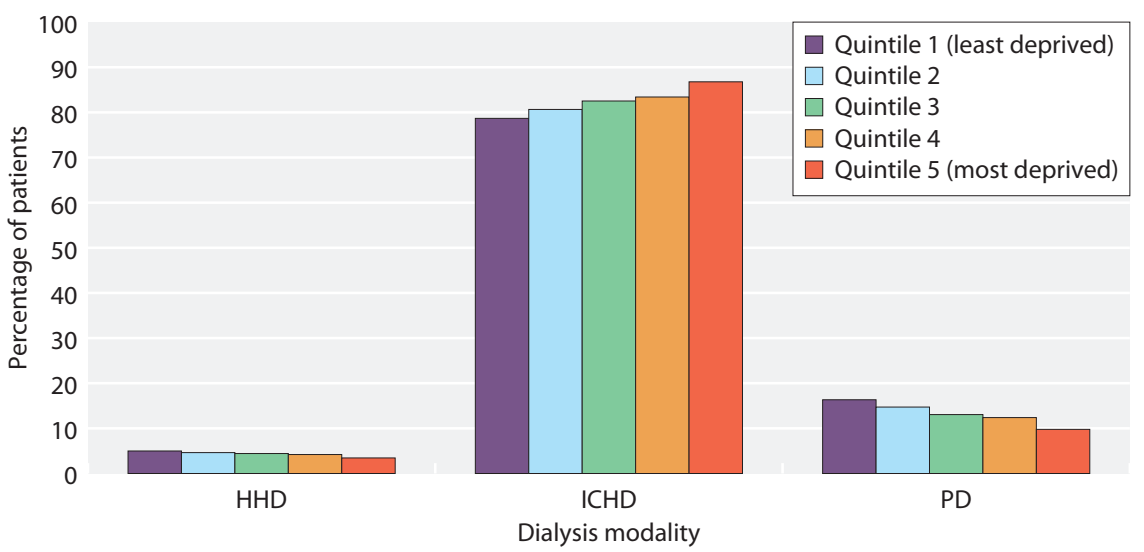

Fig. 13.7. Level of social deprivation in the prevalent dialysis population, by dialysis modality, on 31st December 2015 respectively. This pattern was also seen for transplantation by day 90 , with $12.9 \%$ and $7.0 \%$ of patients from the least and most deprived quintiles respectively. Both of these trends have a clear dose-response pattern. A sensitivity analysis excluding late referrals gives consistent results. It therefore seems reasonable to conclude that increasing deprivation was associated with decreasing HT use, and that this is consistent when accounting for ethnicity, early referrals and early changes in modality.

\section{Comorbidities}

Using centres with $>70 \%$ completeness for comorbidity data, the distribution of comorbidities within the prevalent dialysis population is shown in table 13.6 and figure 13.8. The highest comorbidity was found in the
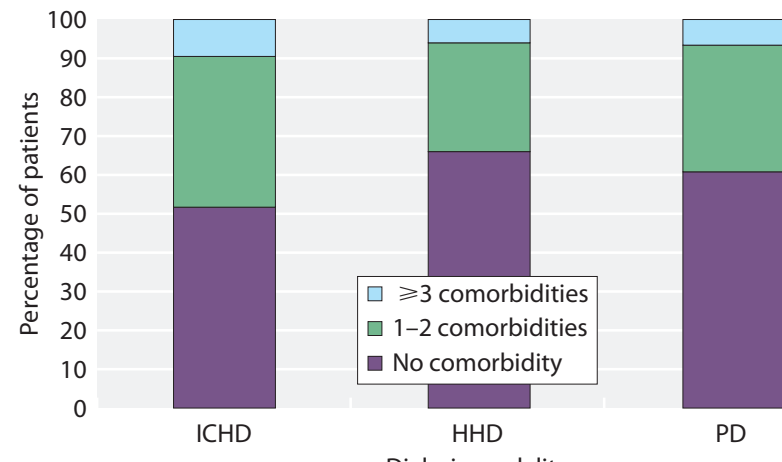

Dialysis modality

Fig. 13.8. Comorbidity of prevalent dialysis patients*, stratified by dialysis modality, on 31st December 2015

* Only data from centres with $\geqslant 70 \%$ completeness for comorbidity data are included

Table 13.6. Comorbidity burden in the prevalent dialysis population, by dialysis modality and centre*, on 31 st December 2015

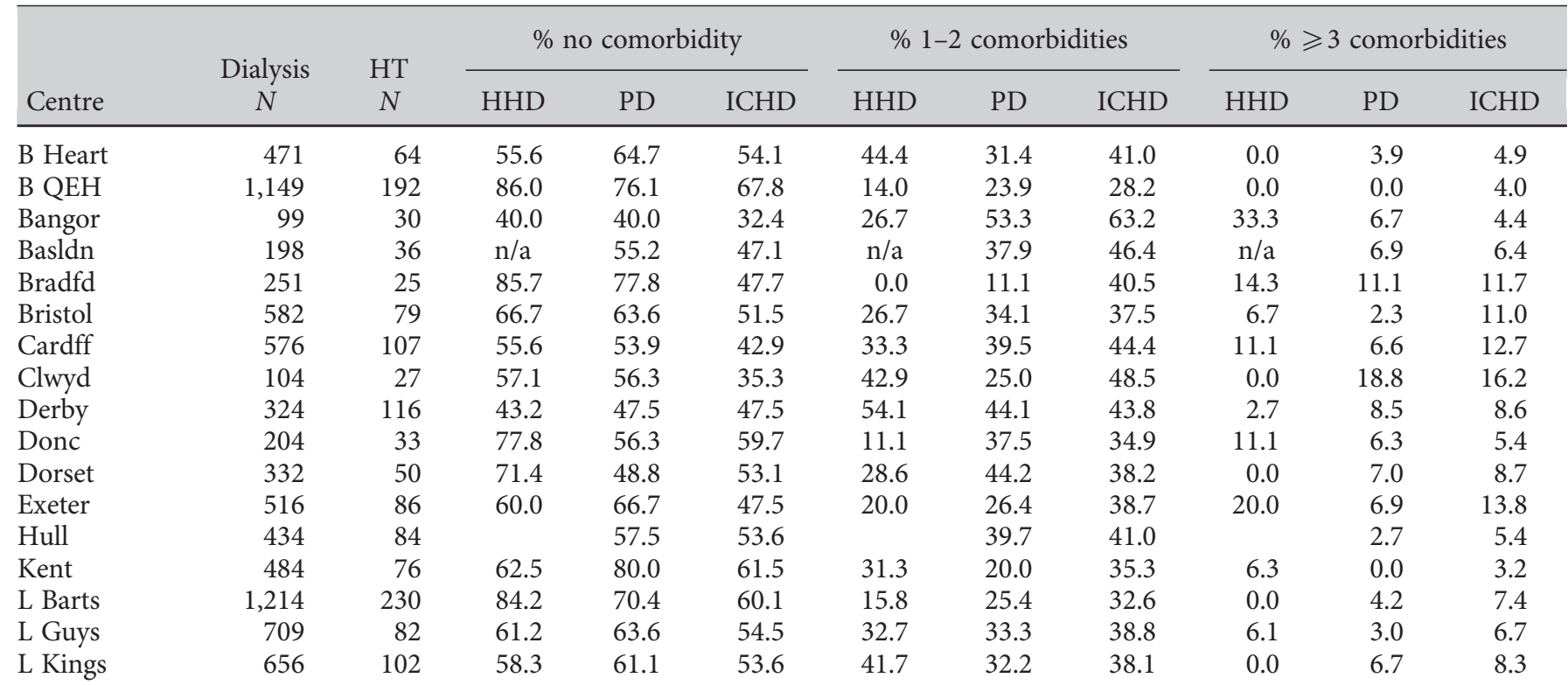


Table 13.6. Continued

\begin{tabular}{|c|c|c|c|c|c|c|c|c|c|c|c|}
\hline \multirow[b]{2}{*}{ Centre } & \multirow{2}{*}{$\begin{array}{c}\text { Dialysis } \\
N\end{array}$} & \multirow{2}{*}{$\begin{array}{c}\mathrm{HT} \\
N\end{array}$} & \multicolumn{3}{|c|}{$\%$ no comorbidity } & \multicolumn{3}{|c|}{$\% 1-2$ comorbidities } & \multicolumn{3}{|c|}{$\% \geqslant 3$ comorbidities } \\
\hline & & & HHD & PD & ICHD & HHD & PD & ICHD & HHD & PD & ICHD \\
\hline Leeds & 570 & 81 & 70.0 & 60.8 & 51.0 & 25.0 & 35.3 & 36.1 & 5.0 & 3.9 & 12.9 \\
\hline Middlbr & 375 & 37 & 72.7 & 77.3 & 39.8 & 27.3 & 18.2 & 45.1 & 0.0 & 4.5 & 15.0 \\
\hline Newc & 361 & 70 & 54.2 & 41.2 & 37.6 & 37.5 & 41.2 & 42.7 & 8.3 & 17.6 & 19.7 \\
\hline Newry & 110 & 25 & 33.3 & 63.6 & 33.8 & 33.3 & 27.3 & 52.7 & 33.3 & 9.1 & 13.5 \\
\hline Nottm & 470 & 111 & 85.7 & 55.2 & 60.3 & 10.7 & 39.7 & 35.1 & 3.6 & 5.2 & 4.6 \\
\hline Oxford & 533 & 113 & 75.0 & 58.7 & 40.5 & 25.0 & 32.0 & 46.2 & 0.0 & 9.3 & 13.3 \\
\hline Plymth & 172 & 42 & 20.0 & 56.5 & 42.3 & 60.0 & 34.8 & 41.2 & 20.0 & 8.7 & 16.5 \\
\hline Redng & 368 & 71 & 80.0 & 42.9 & 33.6 & 20.0 & 39.7 & 47.4 & 0.0 & 17.5 & 19.0 \\
\hline Sheff & 601 & 102 & 59.1 & 58.0 & 50.4 & 40.9 & 40.0 & 42.6 & 0.0 & 2.0 & 7.0 \\
\hline Sthend & 143 & 19 & & 73.3 & 67.4 & & 6.7 & 22.8 & & 20.0 & 9.8 \\
\hline Sund & 239 & 20 & & 77.8 & 53.3 & & 22.2 & 34.3 & & 0.0 & 12.4 \\
\hline Swanse & 427 & 98 & 58.3 & 40.3 & 35.3 & 33.3 & 35.5 & 51.2 & 8.3 & 24.2 & 13.5 \\
\hline Ulster & 112 & 8 & & 50.0 & 34.0 & & 50.0 & 49.0 & & 0.0 & 17.0 \\
\hline West NI & 135 & 16 & 33.3 & 66.7 & 51.0 & 33.3 & 25.0 & 41.2 & 33.3 & 8.3 & 7.8 \\
\hline Wolve & 397 & 102 & 80.0 & 60.3 & 58.1 & 10.0 & 38.4 & 30.5 & 10.0 & 1.4 & 11.4 \\
\hline Wrexm & 149 & 42 & 100.0 & 66.7 & 56.6 & 0.0 & 22.2 & 35.8 & 0.0 & 11.1 & 7.5 \\
\hline York & 189 & 40 & 81.8 & 69.0 & 43.7 & 9.1 & 24.1 & 43.0 & 9.1 & 6.9 & 13.4 \\
\hline Total & 13,654 & 2,416 & 66.0 & 60.8 & 51.7 & 28.0 & 32.6 & 38.8 & 6.0 & 6.6 & 9.5 \\
\hline
\end{tabular}

HT - home therapy; HHD - home haemodialysis; PD - peritoneal dialysis; ICHD - in-centre haemodialysis $\mathrm{n} / \mathrm{a}$ - no patients on this treatment; Blank cells - data for only one to two patients

* Only data from centres with $\geqslant 70 \%$ completeness for comorbidity data are included in this analysis

ICHD group, with HHD having the lowest comorbidity and the PD group an intermediate burden of comorbidity. At centre level, comorbidity burden varied considerably (table 13.6). Despite this, the same pattern of decreasing comorbidity with HT use was evident, although this was clearest in centres with large numbers of HT patients.

\section{Home therapy patient treatment history}

On 31st December 2015 there were 3,537 patients on $\mathrm{PD}$ in the UK. Ignoring temporary changes to HD of fewer than 90 days, these patients had been on PD for a median duration of 1.29 years (interquartile range [IQR] 0.50-2.65 years). Due to previous concerns about technique survival by $\mathrm{PD}$ programme size [5], the association between centre median PD duration and centre programme size was analysed and considerable variation and only a weak association was found (figure 13.9). Modality preceding PD in those patients is shown in figure 13.10 (panel B). The majority of patients (76.4\%) had only ever been on PD, with a median duration on PD of 1.33 years (IQR $0.52-2.73$ years), while a minority had received HD prior to $\mathrm{PD}(17.8 \%$, median duration on PD 1.17 years [IQR $0.42-2.51$ years]) or had had a prior functioning transplant (5.6\%, median duration on $\mathrm{PD}$ 1.06 years [IQR $0.47-2.22$ years]).
The prior modality history for HHD patients was markedly different from PD patients (figure 13.10A), with the great majority having moved onto HHD directly from ICHD (89.5\%). The longer term RRT history was also quite different, with $40.3 \%$ of patients having had a previous transplant, compared with $7.2 \%$ for PD patients. This is at least in part related to the longer time spent on total RRT of the HHD prevalent patients compared to the prevalent PD patients (median time on RRT 7.3 and 1.6 years respectively). Of patients on HHD, $36.8 \%$ had previously been on $\mathrm{PD}$, whilst only $24.3 \%$ of $\mathrm{PD}$ patients had previously been on any form of HD.

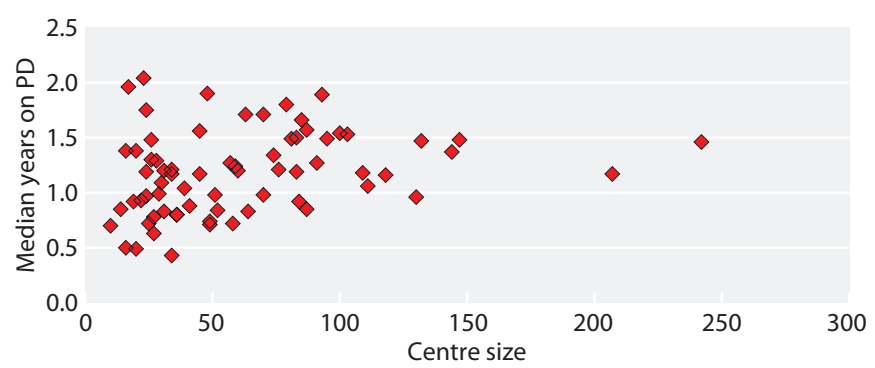

Fig. 13.9. Median duration of $\mathrm{PD}$ by centre size*, in $\mathrm{PD}$ prevalent patients, on 31st December 2015

*Number of incident patients starting RRT on PD during 2013-2015 


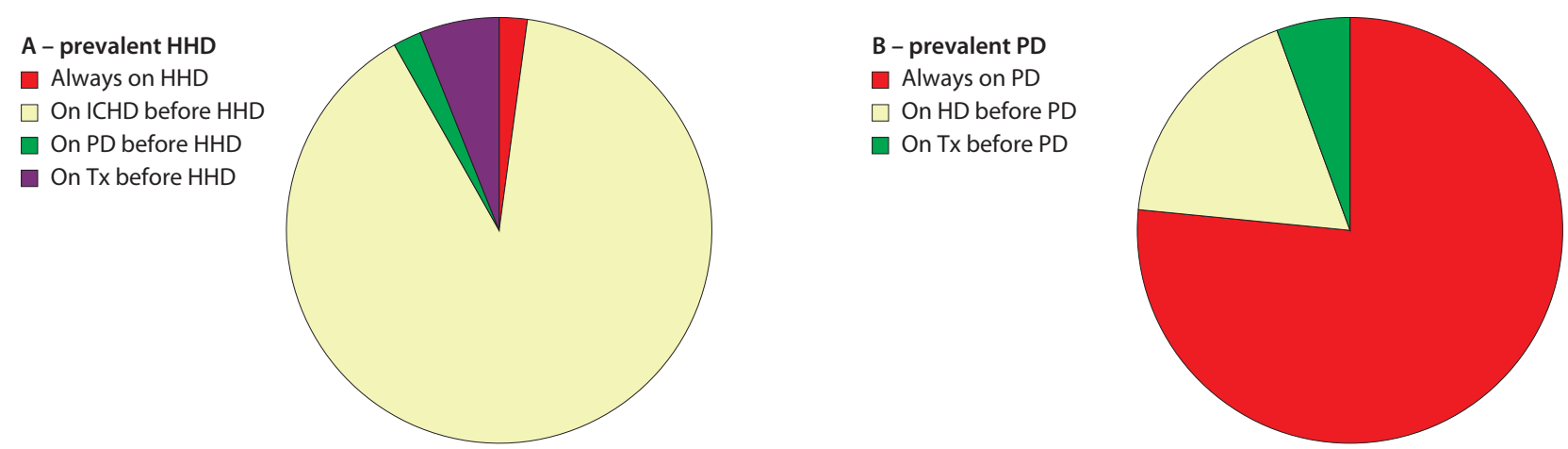

Fig. 13.10. RRT modality immediately prior to HHD in prevalent HHD patients (A) and prior to PD in prevalent PD patients (B)

There were insufficient data to calculate the duration of HHD by centre, but the 1,175 patients on HHD nationally had a median duration of 2.4 years (IQR $0.7-13.2$ years).

\section{Home therapy patient time to starting a home therapy}

The ideal pathway for a HT would minimise the time to starting the HT, reducing time spent on ICHD, but without sacrificing training or support. Time to HT can be seen in figures 13.11 and 13.12, which show the probability of commencing PD or HHD by time since RRT commencement respectively (the cumulative incidence function (CIF) has been used to avoid bias in the presence of competing risks such as death, kidney transplantation or other HT). To aid international comparisons, specifically with ANZDATA, an alternative plot where transplants are censored (appendix 1, figures 13.18 and 13.19) are included. Within the total 2011-2014 incident
RRT cohort, after two years follow-up, $18.0 \%$ of patients had died on ICHD, 1.9\% had been lost to follow-up/had stopped dialysis or had recovered renal function, $13.7 \%$ had received a transplant, $40.3 \%$ remained on ICHD, $2.2 \%$ were on $\mathrm{HHD}$ and $23.9 \%$ were on PD.

Consistent with the data shown in figure 13.10B, the CIF plots show that the majority of patients who were ever going to receive PD started RRT on PD, with some further increase in patients starting PD over the first year of RRT, but little growth after this. The same pattern was evident across all countries, with the differences in HT use between countries described earlier reflected in the height of the CIF curves. HHD has a quite different pattern with almost no patients starting RRT with HHD. With the possible exception of Scotland, there was no evidence of a 'plateau' in the probability of starting HHD by two years after RRT commencement. There was also no evidence of a difference when transplantation was treated as censored or a competing risk.

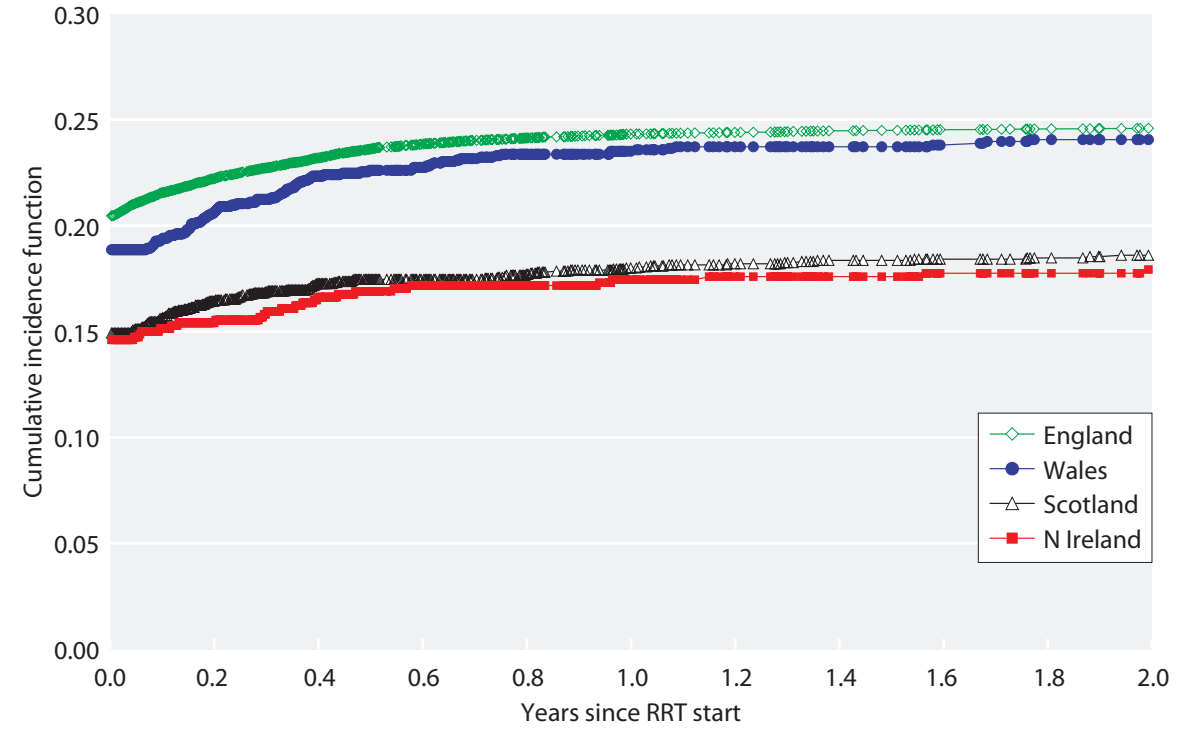

Fig. 13.11. Cumulative probability of starting PD since commencing RRT, by country, in the incident cohort 2011-2014 


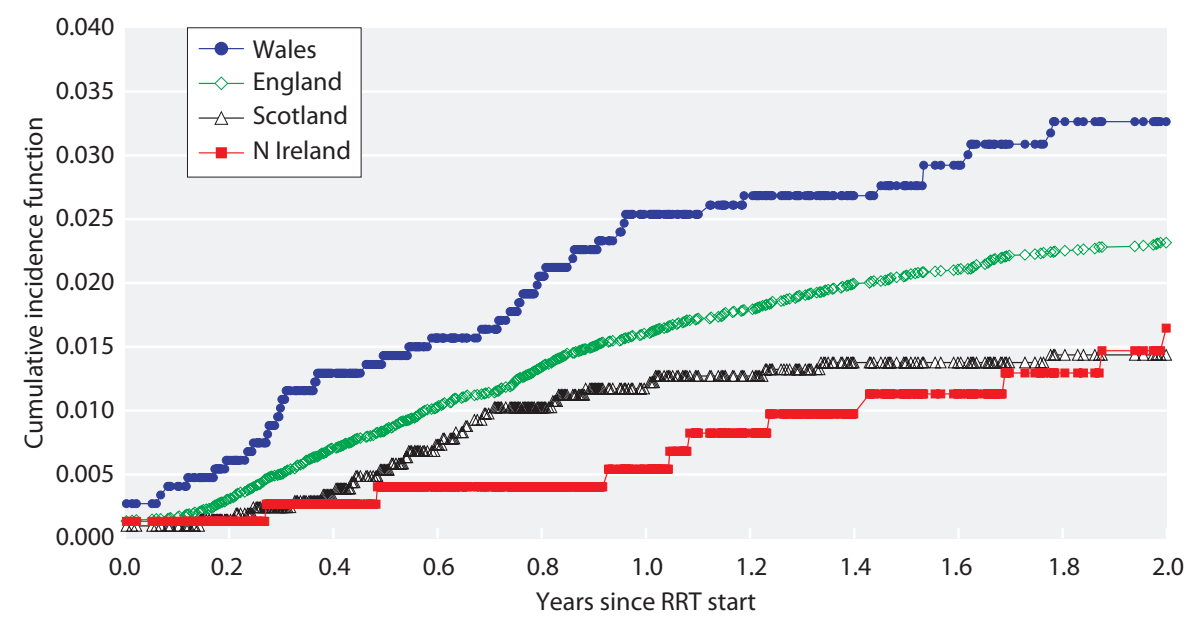

Fig. 13.12. Cumulative probability of starting HHD since commencing RRT, by country, in the incident cohort 2011-2014

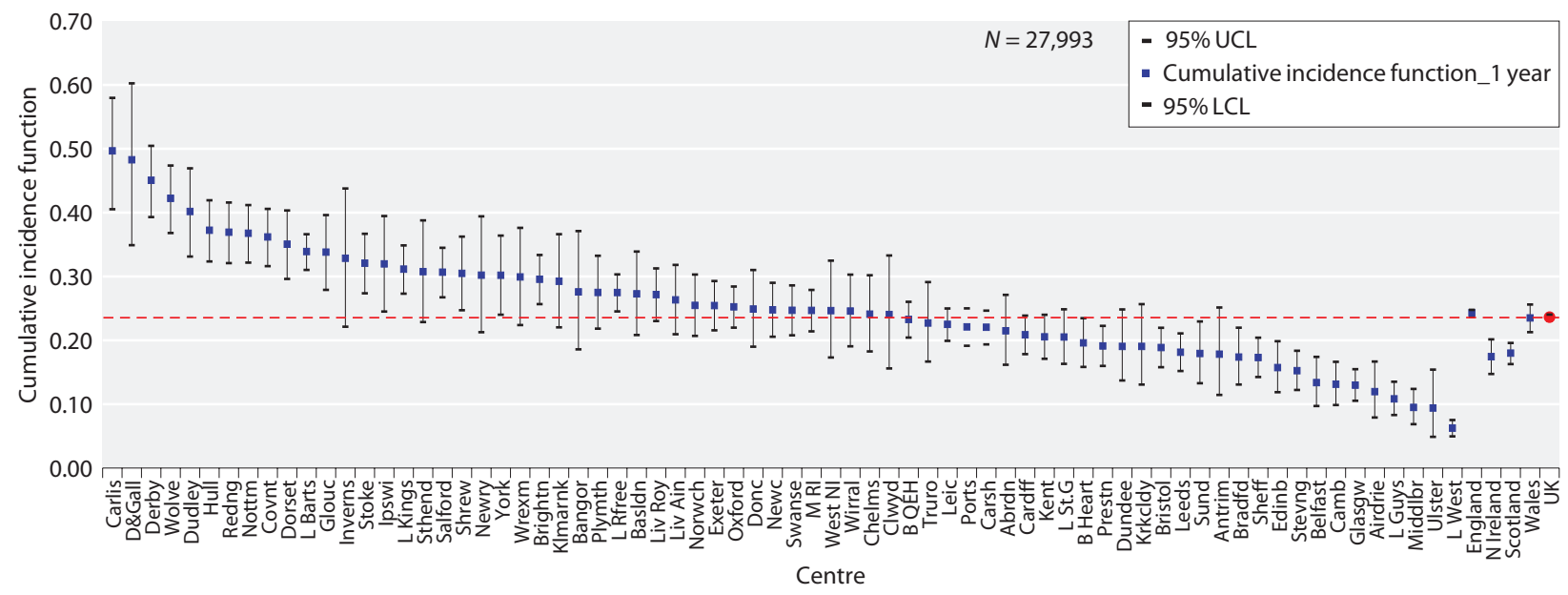

Fig. 13.13A. Cumulative probability of starting PD by one year after RRT start, by centre, in the incident cohort 2011-2014

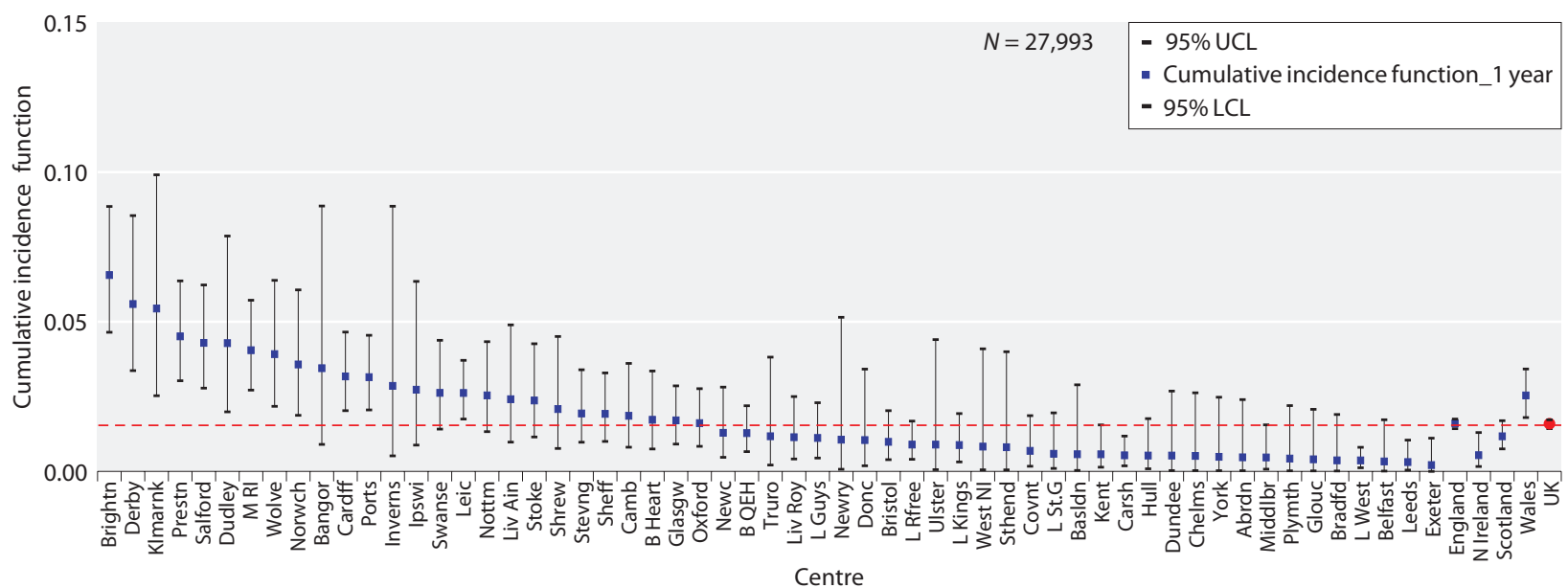

Fig. 13.13B. Cumulative probability of starting HHD by one year after RRT start, by centre, in the incident cohort 2011-2014 
Compared with ANZDATA, which censors these analyses for transplantation, the increase in PD was mostly seen over the first year of RRT, whereas the rise in HHD was more gradual. The absolute values in the UK were lower but the rise in incidence appears to occur over the same time period [2].

For comparison, the time to death and time to transplantation CIFs have been derived for each country. No large differences in time to transplant could be seen between countries, but when assessing time to death, following adjustment for age of start and gender, Wales showed significantly higher incidence compared to England.

Analyses of PD and HHD uptake by centre are shown in figures $13.13 \mathrm{~A}$ and $13.13 \mathrm{~B}$. The extent of variability between centres in PD use is unusual when compared with other UKRR analyses, with the 95\% CI for only 34 centres crossing the national average. The magnitude of the difference between centres is also striking, with the percentage of patients starting PD by one year of RRT start ranging between $6 \%$ and 50\% (CIF 0.06-0.50), an eight-fold difference. There was clear between centre variability in HHD use as well, with the percentage of patients starting HHD by one year of RRT start ranging between $0.2 \%$ and $6.6 \%$ (CIF 0.002-0.066).

\section{Home therapy patient outcomes}

The analysis of outcomes for HTs is more complex due to multiple possible outcomes, which may be either desired (transplantation and rarely recovery) or undesired (death and technique failure). Changes in the probability of any one of these events may change the probability of the other events, so data is provided on all the outcomes to aid interpretation. The numbers on HHD were too small to analyse, with only 1,212 patients starting HHD within two years of RRT start in the UK incident RRT cohort between 2007 and 2014. Of these, 91\% had had ICHD prior to HHD, $1 \%$ had had a transplant prior to HHD and $11 \%$ had had PD prior to HHD.

PD technique outcomes in 9,337 incident PD patients are shown in figure 13.14. This figure describes the cumulative incidence probability for the three possible events of interest in incident PD patients: PD technique-failure (switch to HD), transplantation and death on PD. This analysis was done on a cohort of incident RRT patients from 2007-2014, starting RRT on PD at day zero and still on PD at day 90.

As suggested by work from ANZDATA, the definition used for transfer to ICHD was a switch that lasted for more than 30 days [6]. As shown in figure 13.14, whilst England, Scotland and Northern Ireland had broadly
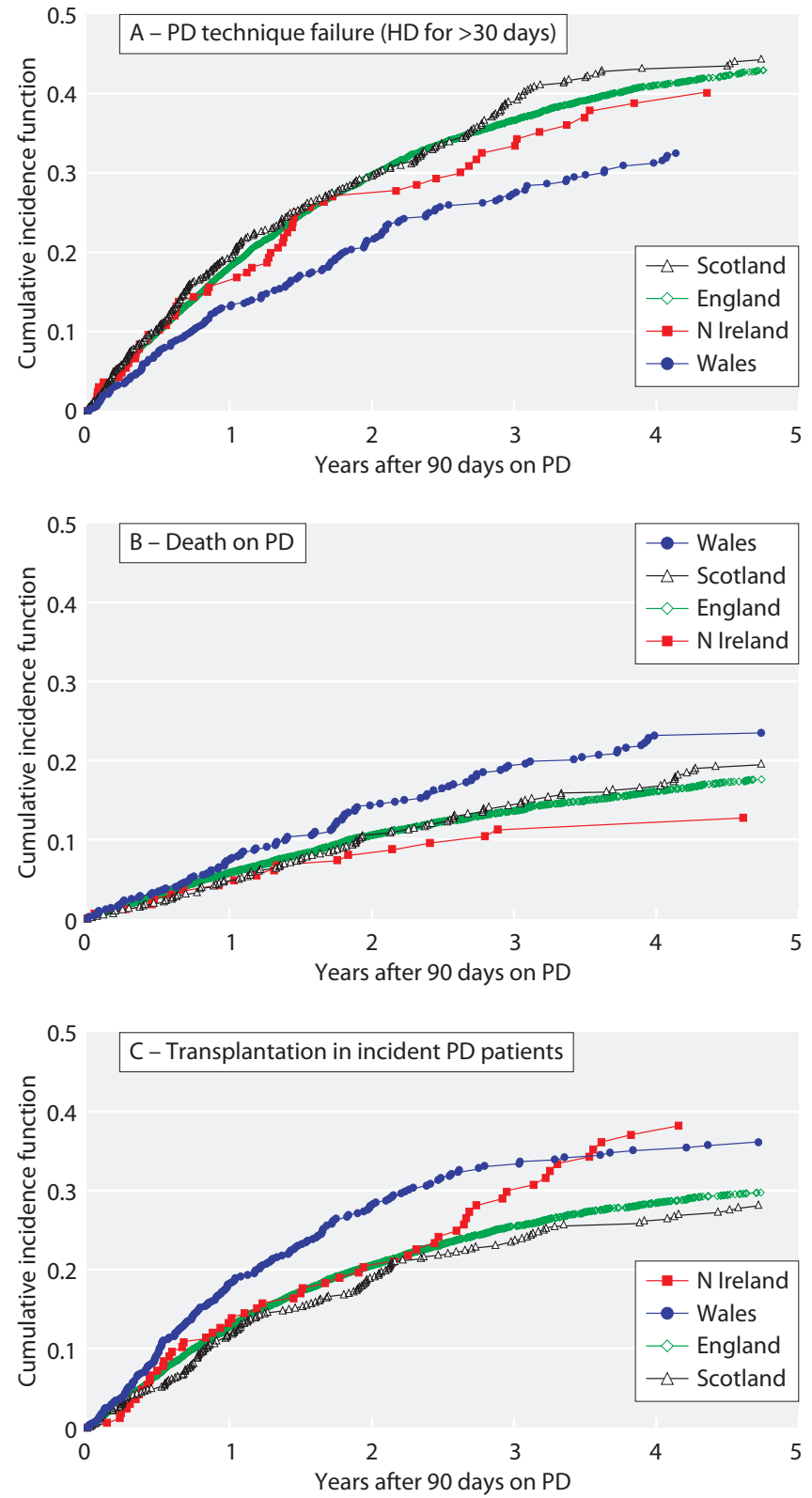

Fig. 13.14. Cumulative probability of technique failure (switch to $\mathrm{HD}$, panel A), mortality on $\mathrm{PD}$ (panel B) and transplantation (panel C), in incident PD* patients 2007-2014, by country *Patients starting RRT on PD at day zero and consecutively on PD for the first 90 days of RRT

comparable event rates for mortality, transplantation and technique failure, there is a suggestion that Wales had slightly higher transplant and mortality rates with possibly as a consequence, a slightly lower technique failure rate. This analysis is not adjusted for patientlevel confounders such as age.

There was also significant between centre variability in technique failure rates, as shown in figure 13.15, with six 

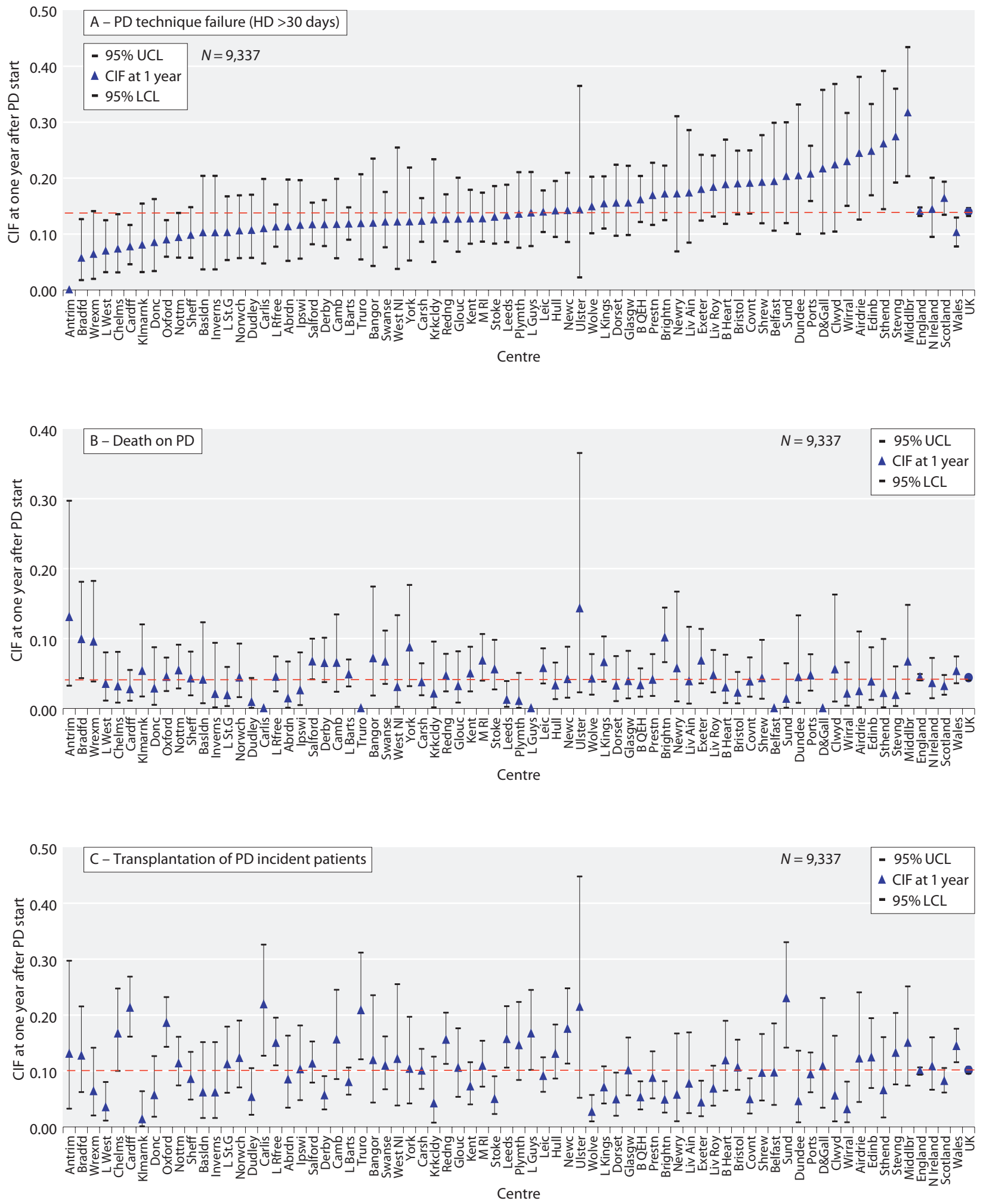

Fig. 13.15. One-year probability of technique failure (switch to HD, panel A), mortality on PD (panel B) and transplantation (panel C),

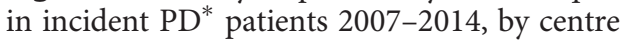

$\mathrm{CIF}=$ cumulative incidence function

*Patients starting RRT on PD at day zero and consecutively on PD for the first 90 days of RRT 


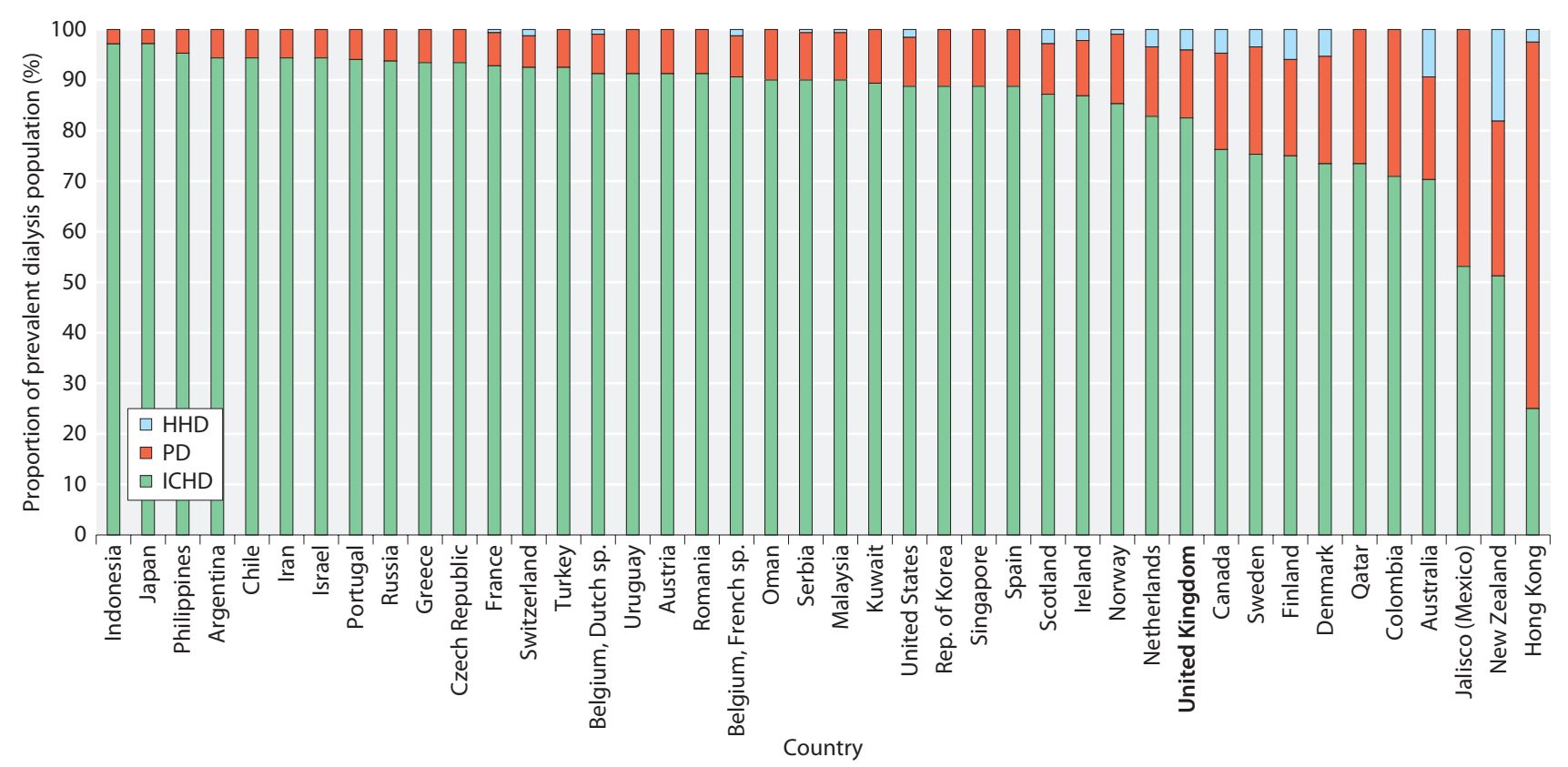

Fig. 13.16. Dialysis modality use by nation, 2014

centres having lower confidence limits that do not cross the national average, and five having upper confidence limits that do not cross the national average. The centre estimates range from a probability of 0.00 to 0.32 . The plots for mortality and transplantation are shown ordered by technique failure rates to visually test whether centre variability in technique failure rates may be partially explained by the other outcomes. There was no apparent pattern. It should be borne in mind that none of these probabilities have been adjusted for potential patient-level confounders such as age.

\section{Home therapies international comparison}

HT prevalence rates internationally vary widely. As seen in figure 13.16, which shows the proportion of prevalent dialysis patients on each modality in 2014 as reported to the United States Renal Data System (USRDS) by registries around the world [7]. HT prevalence was particularly high in countries such as Hong Kong, where a PD first policy was used, whereas in countries like Japan, HT prevalence was less than 5\%. Furthermore, as can be seen in figure 13.17, which looks at the serial change in the proportion of dialysis

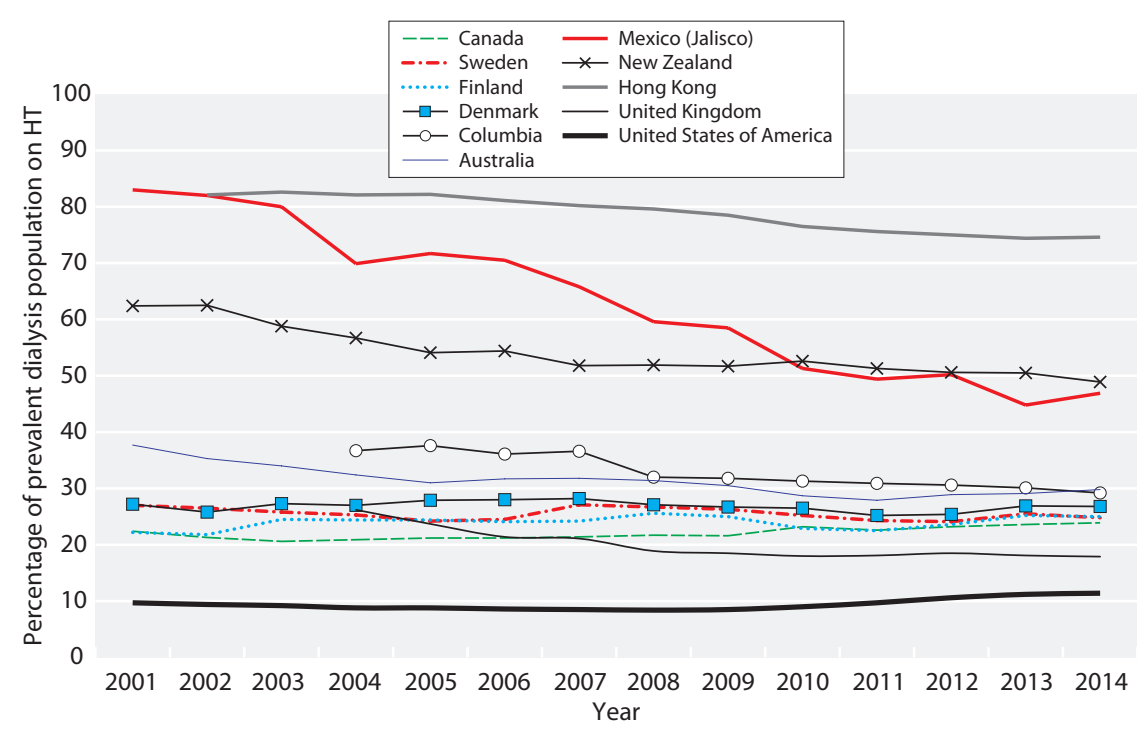

Fig. 13.17. Serial changes in proportion of prevalent dialysis patients using HTs (2001-2014, USRDS) 
patients using a HT in the prevalent dialysis population between 2001-2014 in the top 15 providers of HT internationally, most countries were seeing gradual declines in HT prevalence. Such international differences in dialysis practices may be explained by multiple factors, including geography and climatic factors, healthcare structure, ethical approaches to conservative care and resourcing differences.

\section{Discussion}

This chapter has provided a clear description of the characteristics of the home dialysis population. Whilst many of the characteristics were expected (e.g. lower levels of deprivation, younger age, fewer comorbidities), or unsurprising (fewer ethnic minority patients), the interaction between gender and age was not expected and represents a novel finding. However, these findings are all purely descriptive and the mechanism for these differences remains unclear, making recommendations for changes in practice not possible.

There has also been a preliminary analysis to explore the determinants of the changes in prevalence of HHD and PD over time, with a suggestion that increasing transplantation is the primary driver of the falling $\mathrm{PD}$ prevalence and less of an impact on HHD. This requires a more robust exploration, examining the relative impact on starting versus stopping $\mathrm{PD}$ and $\mathrm{HHD}$, including adjustments for patient mix. This work should also explore the extent to which HHD and PD compete for the same patient population. The results here suggest that the impact will be minimal, with the younger, less comorbid HHD patients usually having a far longer

\section{References}

1 Verduijn M, Grootendorst C, Dekkeri FW, Jager K and Le-Cassie S. The analysis of competing events like cause-specific mortality - beware of the Kaplan-Meier method. Nephrol Dial Transplant 2011, 26:56-61.

2 http://www.anzdata.org.au/v1/report_2016.html

3 Combes G, Allen K, Sein K, Girling A, Lilford R. Taking hospital treatments home: a mixed methods case study looking at the barriers and success factors for home dialysis treatment and the influence of a target on uptake rates. Implement Sci 2015, 10:148.

4 Nitsch D, Steenkamp R, Tomson CRV, Roderick P, Ansell D, MacGregor MS. Outcomes in patients on home haemodialysis in England and history of RRT (including previous PD), implying that HHD is being used for a particular sub-group of patients at a different point in their RRT pathway.

From the point of view of both patient outcomes and treatment costs, it is tempting to explore other areas, such as differences in HHD outcomes and the impact of different practice patterns, including assisted PD. This would require further work on data accuracy and coding and is therefore contingent on the prioritisation of home dialysis data.

Whilst the routine description of patient characteristics is an important feature of this chapter, one of the key strengths of the UKRR is the ability to compare outcomes in different centres. This analysis has robustly demonstrated significant differences between centres in both uptake of $\mathrm{PD} / \mathrm{HHD}$ and outcomes for PD. These differences are large so, although it is possible that variability in patient mix (e.g. ethnicity, deprivation, comorbidity and age) could explain them, it seems unlikely that the differences will disappear after adjustment. This will be tested in subsequent analyses.

\section{Acknowledgement}

The (non-UK) data reported in the section on International comparisons have been supplied by the United States Renal Data System (USRDS). The interpretation and reporting of these data are the responsibility of the author(s) and in no way should be seen as an official policy or interpretation of the U.S. government.

Conflicts of interest: the authors declare no conflicts of interest
Wales, 1997-2005: a comparative cohort analysis. Nephrol Dial Transplant 2011, 26:1670-7.

5 Huisman RM, Nieuwenhuizen MGM, Th de Charro F. Patient-related and centre-related factors influencing technique survival of peritoneal dialysis in The Netherlands. Nephrol Dial Transplant 2002, 17:1655-60.

6 Lan PG, Clayton PA, Johnson DW, McDonald SP, Borlace M, Badve SV, et al. Duration of Hemodialysis Following Peritoneal Dialysis Cessation in Australia and New Zealand: Proposal for a Standardized Definition of Technique Failure. Perit Dial Int 2016, 11-12;36:623-30.

7 https://www.usrds.org/2016/download/v2_c13_IntComp_16.pdf 


\section{Appendix 1}

Table 13.7. Prevalence (as a proportion of the total RRT population) of treatment modalities between 2011 and 2015, by centre

\begin{tabular}{|c|c|c|c|c|c|c|c|}
\hline Centre & Modality & 2011 & 2012 & 2013 & 2014 & 2015 & $\begin{array}{c}\% \text { change } \\
5 \text { years }\end{array}$ \\
\hline \multirow{5}{*}{ Abrdn } & HHD & 0.85 & 1 & 1.38 & 1.22 & 0.95 & 0.1 \\
\hline & $\mathrm{PD}$ & 4.7 & 5 & 4.91 & 5.51 & 4.95 & 0.3 \\
\hline & HT & 5.56 & 6 & 6.29 & 6.73 & 5.9 & 0.3 \\
\hline & $\mathrm{Tx}$ & 49.36 & 48.6 & 51.28 & 53.06 & 53.52 & 4.2 \\
\hline & $\mathrm{HT}+\mathrm{Tx}$ & 54.91 & 54.6 & 57.56 & 59.8 & 59.43 & 4.5 \\
\hline \multirow{5}{*}{ Airdrie } & HHD & 1.17 & 1.27 & 0.63 & 0.62 & 0.59 & -0.6 \\
\hline & $\mathrm{PD}$ & 2.34 & 2.34 & 2.92 & 1.86 & 3.13 & 0.8 \\
\hline & HT & 3.51 & 3.61 & 3.55 & 2.47 & 3.72 & 0.2 \\
\hline & $\mathrm{Tx}$ & 55.74 & 55.2 & 56.58 & 60.21 & 58.12 & 2.4 \\
\hline & $\mathrm{HT}+\mathrm{Tx}$ & 59.25 & 58.81 & 60.13 & 62.68 & 61.84 & 2.6 \\
\hline \multirow{5}{*}{ Antrim } & HHD & 1.96 & 2.77 & 1.55 & 1.13 & 1.45 & -0.5 \\
\hline & $\mathrm{PD}$ & 5.49 & 5.14 & 5.81 & 4.89 & 7.25 & 1.8 \\
\hline & HT & 7.45 & 7.91 & 7.36 & 6.02 & 8.7 & 1.3 \\
\hline & $\mathrm{Tx}$ & 41.96 & 42.29 & 44.57 & 48.12 & 48.19 & 6.2 \\
\hline & $\mathrm{HT}+\mathrm{Tx}$ & 49.41 & 50.2 & 51.94 & 54.14 & 56.88 & 7.5 \\
\hline \multirow{5}{*}{ B Heart } & HHD & 2.88 & 2.08 & 2.57 & 2.17 & 1.58 & -1.3 \\
\hline & PD & 6.02 & 6.11 & 5.13 & 4.34 & 6.2 & 0.2 \\
\hline & HT & 8.9 & 8.19 & 7.7 & 6.51 & 7.79 & -1.1 \\
\hline & $\mathrm{Tx}$ & 35.86 & 37.58 & 39.54 & 42.98 & 42.7 & 6.8 \\
\hline & $\mathrm{HT}+\mathrm{Tx}$ & 44.76 & 45.77 & 47.24 & 49.49 & 50.49 & 5.7 \\
\hline \multirow{5}{*}{ B QEH } & HHD & 2.1 & 2.44 & 2.65 & 2.45 & 2.19 & 0.1 \\
\hline & $\mathrm{PD}$ & 10.01 & 9.23 & 7.72 & 7.79 & 7.41 & -2.6 \\
\hline & HT & 12.11 & 11.67 & 10.37 & 10.25 & 9.6 & -2.5 \\
\hline & $\mathrm{Tx}$ & 37.05 & 37.63 & 40.19 & 40.71 & 40.48 & 3.4 \\
\hline & $\mathrm{HT}+\mathrm{Tx}$ & 49.16 & 49.3 & 50.56 & 50.95 & 50.08 & 0.9 \\
\hline \multirow{5}{*}{ Bangor } & HHD & 8.67 & 9.93 & 11.29 & 10.32 & 9.52 & 0.9 \\
\hline & $\mathrm{PD}$ & 14 & 10.64 & 10.48 & 12.7 & 7.94 & -6.1 \\
\hline & HT & 22.67 & 20.57 & 21.77 & 23.02 & 17.46 & -5.2 \\
\hline & $\mathrm{Tx}$ & 27.33 & 25.53 & 20.16 & 21.43 & 46.03 & 18.7 \\
\hline & $\mathrm{HT}+\mathrm{Tx}$ & 50 & 46.1 & 41.94 & 44.44 & 63.49 & 13.5 \\
\hline \multirow{5}{*}{ Basldn } & HHD & 0.32 & 0.3 & 0.28 & 0.28 & 0.56 & 0.2 \\
\hline & $\mathrm{PD}$ & 8.2 & 9.61 & 8.4 & 7.73 & 9.78 & 1.6 \\
\hline & HT & 8.52 & 9.91 & 8.68 & 8.01 & 10.34 & 1.8 \\
\hline & $\mathrm{Tx}$ & 44.48 & 42.34 & 46.5 & 44.48 & 44.41 & -0.1 \\
\hline & $\mathrm{HT}+\mathrm{Tx}$ & 53 & 52.25 & 55.18 & 52.49 & 54.75 & 1.8 \\
\hline \multirow{5}{*}{ Belfast } & HHD & 2.84 & 3.33 & 2.54 & 1.41 & 1.02 & -1.8 \\
\hline & PD & 5.3 & 4.81 & 4.89 & 2.64 & 4.07 & -1.2 \\
\hline & HT & 8.14 & 8.13 & 7.43 & 4.05 & 5.09 & -3.1 \\
\hline & $\mathrm{Tx}$ & 52.27 & 54.16 & 56.88 & 62.15 & 65.37 & 13.1 \\
\hline & $\mathrm{HT}+\mathrm{Tx}$ & 60.42 & 62.29 & 64.31 & 66.2 & 70.46 & 10.0 \\
\hline \multirow{5}{*}{ Bradfd } & HHD & 0.2 & 0.73 & 1.22 & 1.68 & 1.43 & 1.2 \\
\hline & $\mathrm{PD}$ & 6.26 & 5.26 & 5.21 & 3.52 & 2.87 & -3.4 \\
\hline & HT & 6.46 & 5.99 & 6.42 & 5.2 & 4.3 & -2.2 \\
\hline & $\mathrm{Tx}$ & 55.97 & 56.99 & 59.2 & 58.56 & 59.71 & 3.7 \\
\hline & $\mathrm{HT}+\mathrm{Tx}$ & 62.43 & 62.98 & 65.63 & 63.76 & 64.01 & 1.6 \\
\hline \multirow{5}{*}{ Brightn } & HHD & 3.34 & 4.13 & 4.95 & 5.18 & 4.46 & 1.1 \\
\hline & $\mathrm{PD}$ & 8.91 & 8.89 & 7.98 & 6.14 & 6.22 & -2.7 \\
\hline & HT & 12.25 & 13.02 & 12.93 & 11.31 & 10.68 & -1.6 \\
\hline & $\mathrm{Tx}$ & 52.78 & 51.53 & 51.41 & 52.44 & 53.2 & 0.4 \\
\hline & $\mathrm{HT}+\mathrm{Tx}$ & 65.03 & 64.55 & 64.34 & 63.76 & 63.88 & -1.2 \\
\hline
\end{tabular}


Table 13.7. Continued

\begin{tabular}{|c|c|c|c|c|c|c|c|}
\hline Centre & Modality & 2011 & 2012 & 2013 & 2014 & 2015 & $\begin{array}{c}\% \text { change } \\
5 \text { years }\end{array}$ \\
\hline \multirow{5}{*}{ Bristol } & HHD & 2.12 & 2.04 & 1.63 & 1.36 & 1.27 & -0.9 \\
\hline & PD & 5.5 & 5.38 & 5.21 & 5.05 & 4.25 & -1.3 \\
\hline & HT & 7.62 & 7.42 & 6.84 & 6.4 & 5.52 & -2.1 \\
\hline & $\mathrm{Tx}$ & 55.04 & 54.81 & 55.48 & 55.5 & 56.97 & 1.9 \\
\hline & $\mathrm{HT}+\mathrm{Tx}$ & 62.66 & 62.23 & 62.32 & 61.9 & 62.49 & -0.2 \\
\hline \multirow{5}{*}{$\mathrm{Camb}^{\mathrm{b}}$} & HHD & 0.84 & 1.3 & 1.82 & 2.23 & & \\
\hline & PD & 4.9 & 4.14 & 2.73 & 3.46 & & \\
\hline & HT & 5.73 & 5.44 & 4.55 & 5.69 & & \\
\hline & $\mathrm{Tx}$ & 51.85 & 54.73 & 54.66 & 55.8 & & \\
\hline & $\mathrm{HT}+\mathrm{Tx}$ & 57.59 & 60.17 & 59.2 & 61.5 & & \\
\hline \multirow{5}{*}{ Cardff } & HHD & 2.3 & 2.12 & 2.71 & 2.4 & 1.82 & -0.5 \\
\hline & $\mathrm{PD}$ & 7.32 & 5.51 & 5.07 & 5.43 & 5.33 & -2.0 \\
\hline & HT & 9.62 & 7.63 & 7.78 & 7.83 & 7.16 & -2.5 \\
\hline & $\mathrm{Tx}$ & 57.36 & 60.59 & 61.15 & 60.71 & 61.17 & 3.8 \\
\hline & $\mathrm{HT}+\mathrm{Tx}$ & 66.98 & 68.22 & 68.94 & 68.54 & 68.33 & 1.3 \\
\hline \multirow{5}{*}{ Carlis } & HHD & 0.47 & 0.46 & 0.43 & 0.4 & 0 & -0.5 \\
\hline & PD & 9.81 & 12.04 & 11.54 & 10.32 & 13.57 & 3.8 \\
\hline & HT & 10.28 & 12.5 & 11.97 & 10.71 & 13.57 & 3.3 \\
\hline & $\mathrm{Tx}$ & 59.81 & 59.26 & 59.4 & 59.92 & 57.5 & -2.3 \\
\hline & $\mathrm{HT}+\mathrm{Tx}$ & 70.09 & 71.76 & 71.37 & 70.63 & 71.07 & 1.0 \\
\hline \multirow{5}{*}{ Carsh } & HHD & 1.1 & 1.24 & 1.55 & 1.61 & 1.85 & 0.8 \\
\hline & $\mathrm{PD}$ & 6.63 & 6.87 & 7.17 & 7.84 & 6.32 & -0.3 \\
\hline & HT & 7.73 & 8.11 & 8.73 & 9.45 & 8.17 & 0.4 \\
\hline & $\mathrm{Tx}$ & 46.65 & 46.78 & 47.34 & 47.03 & 47.87 & 1.2 \\
\hline & $\mathrm{HT}+\mathrm{Tx}$ & 54.39 & 54.89 & 56.07 & 56.48 & 56.04 & 1.7 \\
\hline \multirow{5}{*}{ Chelms } & HHD & 0.29 & 0.28 & 1.1 & 0.77 & 0.29 & 0.0 \\
\hline & $\mathrm{PD}$ & 6.4 & 6.8 & 5.25 & 6.19 & 7.47 & 1.1 \\
\hline & HT & 6.69 & 7.08 & 6.35 & 6.96 & 7.76 & 1.1 \\
\hline & $\mathrm{Tx}$ & 58.43 & 56.09 & 60.22 & 58.51 & 50.86 & -7.6 \\
\hline & $\mathrm{HT}+\mathrm{Tx}$ & 65.12 & 63.17 & 66.57 & 65.46 & 58.62 & -6.5 \\
\hline \multirow{5}{*}{ Clwyd } & HHD & 2.07 & 1.14 & 1.22 & 2.22 & 2.16 & 0.1 \\
\hline & $\mathrm{PD}$ & 5.52 & 10.23 & 7.93 & 6.11 & 10.81 & 5.3 \\
\hline & HT & 7.59 & 11.36 & 9.15 & 8.33 & 12.97 & 5.4 \\
\hline & $\mathrm{Tx}$ & 51.72 & 42.61 & 46.34 & 43.89 & 45.41 & -6.3 \\
\hline & $\mathrm{HT}+\mathrm{Tx}$ & 59.31 & 53.98 & 55.49 & 52.22 & 58.38 & -0.9 \\
\hline \multirow{5}{*}{ Colchr } & HHD & 0.39 & 0.38 & 0 & 0 & 0 & -0.4 \\
\hline & $\mathrm{PD}$ & 3.52 & 3.8 & 2.97 & 3.08 & 4.42 & 0.9 \\
\hline & HT & 3.91 & 4.18 & 2.97 & 3.08 & 4.42 & 0.5 \\
\hline & $\mathrm{Tx}$ & 49.61 & 51.33 & 54.28 & 56.16 & 42.48 & -7.1 \\
\hline & $\mathrm{HT}+\mathrm{Tx}$ & 53.52 & 55.51 & 57.25 & 59.25 & 46.9 & -6.6 \\
\hline \multirow{5}{*}{ Covnt } & HHD & 1.47 & 2.11 & 2.08 & 1.23 & 1.67 & 0.2 \\
\hline & $\mathrm{PD}$ & 10.93 & 11.61 & 9.69 & 10.59 & 9.57 & -1.4 \\
\hline & HT & 12.41 & 13.72 & 11.76 & 11.82 & 11.23 & -1.2 \\
\hline & $\mathrm{Tx}$ & 45.21 & 46.19 & 47.06 & 48.61 & 51.17 & 6.0 \\
\hline & $\mathrm{HT}+\mathrm{Tx}$ & 57.62 & 59.91 & 58.82 & 60.42 & 62.4 & 4.8 \\
\hline \multirow{5}{*}{ D \& Gall } & HHD & 0.8 & 0.79 & 1.63 & 1.54 & 2.19 & 1.4 \\
\hline & $\mathrm{PD}$ & 11.2 & 12.6 & 12.2 & 11.54 & 8.03 & -3.2 \\
\hline & HT & 12 & 13.39 & 13.82 & 13.08 & 10.22 & -1.8 \\
\hline & $\mathrm{Tx}$ & 48.8 & 48.03 & 49.59 & 51.54 & 52.55 & 3.8 \\
\hline & $\mathrm{HT}+\mathrm{Tx}$ & 60.8 & 61.42 & 63.41 & 64.62 & 62.77 & 2.0 \\
\hline
\end{tabular}


Table 13.7. Continued

\begin{tabular}{|c|c|c|c|c|c|c|c|}
\hline Centre & Modality & 2011 & 2012 & 2013 & 2014 & 2015 & $\begin{array}{c}\% \text { change } \\
5 \text { years }\end{array}$ \\
\hline \multirow{5}{*}{ Derby } & HHD & 3.06 & 4.5 & 4.71 & 5.27 & 5.42 & 2.4 \\
\hline & $\mathrm{PD}$ & 20 & 15.83 & 14.31 & 14 & 12.44 & -7.6 \\
\hline & HT & 23.06 & 20.32 & 19.02 & 19.28 & 17.86 & -5.2 \\
\hline & & 42.88 & 44.6 & 48.69 & 47.45 & 48.96 & 6.1 \\
\hline & $\mathrm{HT}+\mathrm{Tx}$ & 65.95 & 64.93 & 67.71 & 66.72 & 66.83 & 0.9 \\
\hline \multirow{5}{*}{ Donc } & HHD & 2.35 & 1.95 & 2.79 & 4.09 & 3.79 & 1.4 \\
\hline & $\mathrm{PD}$ & 7.65 & 8.08 & 9.75 & 6.91 & 5.81 & -1.8 \\
\hline & HT & 10 & 10.03 & 12.53 & 11 & 9.6 & -0.4 \\
\hline & $\mathrm{Tx}$ & 42.65 & 42.06 & 42.34 & 44.25 & 47.22 & 4.6 \\
\hline & $\mathrm{HT}+\mathrm{Tx}$ & 52.65 & 52.09 & 54.87 & 55.24 & 56.82 & 4.2 \\
\hline \multirow{5}{*}{ Dorset } & HHD & 0.76 & 0.6 & 1.01 & 1.39 & 1.49 & 0.7 \\
\hline & $\mathrm{PD}$ & 7.9 & 7 & 6.81 & 7.08 & 5.83 & -2.1 \\
\hline & HT & 8.66 & 7.6 & 7.83 & 8.47 & 7.32 & -1.3 \\
\hline & Tx & 54.86 & 53.65 & 53.91 & 53.89 & 54.61 & -0.3 \\
\hline & $\mathrm{HT}+\mathrm{Tx}$ & 63.53 & 61.25 & 61.74 & 62.36 & 61.92 & -1.6 \\
\hline \multirow{5}{*}{ Dudley } & HHD & 3.58 & 5.06 & 4.7 & 5.41 & 4.75 & 1.2 \\
\hline & PD & 15.82 & 17.42 & 15.47 & 14.59 & 15.04 & -0.8 \\
\hline & HT & 19.4 & 22.47 & 20.17 & 20 & 19.79 & 0.4 \\
\hline & $\mathrm{Tx}$ & 37.91 & 33.15 & 35.08 & 36.76 & 38.26 & 0.4 \\
\hline & $\mathrm{HT}+\mathrm{Tx}$ & 57.31 & 55.62 & 55.25 & 56.76 & 58.05 & 0.7 \\
\hline \multirow{5}{*}{ Dundee } & HHD & 0.25 & 0.25 & 1 & 0.99 & 0.47 & 0.2 \\
\hline & PD & 4.75 & 4.81 & 5 & 5.69 & 3.99 & -0.8 \\
\hline & HT & 5 & 5.06 & 6 & 6.68 & 4.46 & -0.5 \\
\hline & $\mathrm{Tx}$ & 49.25 & 49.87 & 52.25 & 52.72 & 52.11 & 2.9 \\
\hline & $\mathrm{HT}+\mathrm{Tx}$ & 54.25 & 54.94 & 58.25 & 59.41 & 56.57 & 2.3 \\
\hline \multirow{5}{*}{ Edinb } & HHD & 0.9 & 0.87 & 0.72 & 0.85 & 0.95 & 0.0 \\
\hline & $\mathrm{PD}$ & 5.99 & 5.52 & 4.32 & 2.98 & 3.65 & -2.3 \\
\hline & HT & 6.89 & 6.39 & 5.04 & 3.84 & 4.59 & -2.3 \\
\hline & $\mathrm{Tx}$ & 55.39 & 56.17 & 56.55 & 58.95 & 57.84 & 2.5 \\
\hline & $\mathrm{HT}+\mathrm{Tx}$ & 62.28 & 62.55 & 61.58 & 62.78 & 62.43 & 0.1 \\
\hline \multirow{5}{*}{ Exeter } & HHD & 0.44 & 0.43 & 0.41 & 0.39 & 0.48 & 0.0 \\
\hline & $\mathrm{PD}$ & 8.46 & 8.12 & 7.47 & 9.06 & 7.72 & -0.7 \\
\hline & HT & 8.9 & 8.55 & 7.88 & 9.45 & 8.2 & -0.7 \\
\hline & $\mathrm{Tx}$ & 50 & 49.68 & 51.28 & 50.92 & 50.81 & 0.8 \\
\hline & $\mathrm{HT}+\mathrm{Tx}$ & 58.9 & 58.23 & 59.16 & 60.37 & 59.01 & 0.1 \\
\hline \multirow{5}{*}{ Glasgw } & HHD & 2.04 & 2.03 & 1.7 & 1.68 & 1.39 & -0.7 \\
\hline & $\mathrm{PD}$ & 3.57 & 3.29 & 3 & 2.62 & 3.48 & -0.1 \\
\hline & HT & 5.6 & 5.33 & 4.7 & 4.3 & 4.87 & -0.7 \\
\hline & $\mathrm{Tx}$ & 51.46 & 53.82 & 56.34 & 59.54 & 58.48 & 7.0 \\
\hline & $\mathrm{HT}+\mathrm{Tx}$ & 57.06 & 59.15 & 61.04 & 63.84 & 63.35 & 6.3 \\
\hline \multirow{5}{*}{ Glouc } & HHD & 1.5 & 1.46 & 1.21 & 1.98 & 1.53 & 0.0 \\
\hline & PD & 8.33 & 7.48 & 6.68 & 8.53 & 7.06 & -1.3 \\
\hline & HT & 9.83 & 8.94 & 7.89 & 10.52 & 8.59 & -1.2 \\
\hline & $\mathrm{Tx}$ & 48.93 & 46.15 & 49.6 & 48.02 & 48.85 & -0.1 \\
\hline & $\mathrm{HT}+\mathrm{Tx}$ & 58.76 & 55.09 & 57.49 & 58.53 & 57.44 & -1.3 \\
\hline \multirow{5}{*}{ Hull } & HHD & 1.12 & 1.32 & 1.05 & 1.15 & 1.18 & 0.1 \\
\hline & $\mathrm{PD}$ & 11.07 & 10.94 & 9.3 & 8.82 & 8.16 & -2.9 \\
\hline & HT & 12.19 & 12.26 & 10.35 & 9.97 & 9.34 & -2.9 \\
\hline & $\mathrm{Tx}$ & 49.63 & 50 & 52.67 & 53.49 & 53.06 & 3.4 \\
\hline & $\mathrm{HT}+\mathrm{Tx}$ & 61.82 & 62.26 & 63.02 & 63.46 & 62.41 & 0.6 \\
\hline
\end{tabular}


Table 13.7. Continued

\begin{tabular}{|c|c|c|c|c|c|c|c|}
\hline Centre & Modality & 2011 & 2012 & 2013 & 2014 & 2015 & $\begin{array}{c}\% \text { change } \\
5 \text { years }\end{array}$ \\
\hline \multirow{5}{*}{ Inverns } & HHD & 2.18 & 3.18 & 0.91 & 1.32 & 1.57 & -0.6 \\
\hline & $\mathrm{PD}$ & 7.42 & 7.27 & 5.94 & 6.58 & 5.12 & -2.3 \\
\hline & HT & 9.61 & 10.45 & 6.85 & 7.89 & 6.69 & -2.9 \\
\hline & $\mathrm{Tx}$ & 55.9 & 58.64 & 62.1 & 63.16 & 57.87 & 2.0 \\
\hline & $\mathrm{HT}+\mathrm{Tx}$ & 65.5 & 69.09 & 68.95 & 71.05 & 64.57 & -0.9 \\
\hline \multirow{5}{*}{ Ipswi } & HHD & 1.34 & 1 & 0.63 & 0.91 & 0 & -1.3 \\
\hline & $\mathrm{PD}$ & 8.7 & 8.33 & 7.84 & 8.18 & 8.7 & 0.0 \\
\hline & HT & 10.03 & 9.33 & 8.46 & 9.09 & 8.7 & -1.3 \\
\hline & $\mathrm{Tx}$ & 49.83 & 49.33 & 53.92 & 53.64 & 49.86 & 0.0 \\
\hline & $\mathrm{HT}+\mathrm{Tx}$ & 59.87 & 58.67 & 62.38 & 62.73 & 58.55 & -1.3 \\
\hline \multirow{5}{*}{ Kent } & HHD & 2.39 & 2.17 & 2.18 & 1.89 & 1.67 & -0.7 \\
\hline & $\mathrm{PD}$ & 7.05 & 6.21 & 6.07 & 5.95 & 5.29 & -1.8 \\
\hline & HT & 9.44 & 8.37 & 8.25 & 7.84 & 6.96 & -2.5 \\
\hline & Tx & 53.73 & 55.76 & 56.68 & 57.08 & 57.09 & 3.4 \\
\hline & $\mathrm{HT}+\mathrm{Tx}$ & 63.17 & 64.14 & 64.93 & 64.92 & 64.05 & 0.9 \\
\hline \multirow{5}{*}{ Klmarnk } & HHD & 2.08 & 2.59 & 2.03 & 3.17 & 2.54 & 0.5 \\
\hline & $\mathrm{PD}$ & 13.35 & 11.82 & 12.46 & 10.37 & 10.42 & -2.9 \\
\hline & HT & 15.43 & 14.41 & 14.49 & 13.54 & 12.96 & -2.5 \\
\hline & $\mathrm{Tx}$ & 43.03 & 44.67 & 47.83 & 50.72 & 51.55 & 8.5 \\
\hline & $\mathrm{HT}+\mathrm{Tx}$ & 58.46 & 59.08 & 62.32 & 64.27 & 64.51 & 6.1 \\
\hline \multirow{5}{*}{ Krkcldy } & HHD & 0 & 0 & 0 & 0 & 0 & 0.0 \\
\hline & $\mathrm{PD}$ & 9.79 & 6.99 & 6.53 & 5.21 & 6.54 & -3.3 \\
\hline & HT & 9.79 & 6.99 & 6.53 & 5.21 & 6.54 & -3.3 \\
\hline & $\mathrm{Tx}$ & 39.16 & 41.61 & 42.96 & 45.14 & 44.44 & 5.3 \\
\hline & $\mathrm{HT}+\mathrm{Tx}$ & 48.95 & 48.6 & 49.48 & 50.35 & 50.98 & 2.0 \\
\hline \multirow{5}{*}{ L Barts } & HHD & 0.46 & 0.71 & 0.46 & 0.62 & 0.96 & 0.5 \\
\hline & $\mathrm{PD}$ & 9.57 & 10.43 & 9.8 & 10.63 & 9.45 & -0.1 \\
\hline & HT & 10.03 & 11.14 & 10.26 & 11.25 & 10.41 & 0.4 \\
\hline & $\mathrm{Tx}$ & 40.08 & 41.1 & 42.19 & 43.85 & 44.7 & 4.6 \\
\hline & $\mathrm{HT}+\mathrm{Tx}$ & 50.12 & 52.24 & 52.45 & 55.1 & 55.11 & 5.0 \\
\hline \multirow{5}{*}{ L Guys } & HHD & 1.63 & 1.92 & 2.1 & 2.48 & 1.75 & 0.1 \\
\hline & $\mathrm{PD}$ & 2.99 & 2.7 & 2.43 & 2.32 & 2.5 & -0.5 \\
\hline & HT & 4.62 & 4.62 & 4.53 & 4.8 & 4.25 & -0.4 \\
\hline & $\mathrm{Tx}$ & 43.66 & 44.43 & 46.44 & 47.24 & 48.18 & 4.5 \\
\hline & $\mathrm{HT}+\mathrm{Tx}$ & 48.28 & 49.04 & 50.96 & 52.04 & 52.43 & 4.2 \\
\hline \multirow{5}{*}{ L Kings } & HHD & 1.14 & 1.54 & 1.18 & 1.59 & 1.51 & 0.4 \\
\hline & $\mathrm{PD}$ & 8.48 & 7.77 & 8.79 & 7.23 & 6.81 & -1.7 \\
\hline & HT & 9.62 & 9.3 & 9.97 & 8.82 & 8.33 & -1.3 \\
\hline & $\mathrm{Tx}$ & 46.29 & 47.06 & 48.27 & 49.05 & 49.74 & 3.5 \\
\hline & $\mathrm{HT}+\mathrm{Tx}$ & 55.9 & 56.37 & 58.24 & 57.87 & 58.06 & 2.2 \\
\hline \multirow{5}{*}{ L Rfree } & HHD & 1.05 & 1.16 & 1.17 & 1.02 & 1.31 & 0.3 \\
\hline & PD & 6.09 & 7.34 & 7.74 & 8.05 & 8.33 & 2.2 \\
\hline & HT & 7.13 & 8.51 & 8.91 & 9.08 & 9.64 & 2.5 \\
\hline & $\mathrm{Tx}$ & 48.89 & 49.88 & 50.26 & 51.56 & 52.69 & 3.8 \\
\hline & $\mathrm{HT}+\mathrm{Tx}$ & 56.02 & 58.38 & 59.18 & 60.64 & 62.33 & 6.3 \\
\hline \multirow{5}{*}{ L St.G } & HHD & 0.9 & 0.59 & 0.7 & 0.92 & 0.87 & 0.0 \\
\hline & $\mathrm{PD}$ & 8.13 & 7.51 & 6.76 & 6.28 & 6.06 & -2.1 \\
\hline & HT & 9.04 & 8.1 & 7.46 & 7.2 & 6.93 & -2.1 \\
\hline & $\mathrm{Tx}$ & 48.8 & 51.69 & 53.66 & 52.75 & 51.73 & 2.9 \\
\hline & $\mathrm{HT}+\mathrm{Tx}$ & 57.83 & 59.79 & 61.13 & 59.95 & 58.66 & 0.8 \\
\hline
\end{tabular}


Table 13.7. Continued

\begin{tabular}{|c|c|c|c|c|c|c|c|}
\hline Centre & Modality & 2011 & 2012 & 2013 & 2014 & 2015 & $\begin{array}{c}\% \text { change } \\
5 \text { years }\end{array}$ \\
\hline \multirow{5}{*}{ L West } & HHD & 0.4 & 0.6 & 0.55 & 0.6 & 0.61 & 0.2 \\
\hline & PD & 1.28 & 1.83 & 2.11 & 2.13 & 2.28 & 1.0 \\
\hline & HT & 1.68 & 2.43 & 2.67 & 2.73 & 2.89 & 1.2 \\
\hline & $\mathrm{Tx}$ & 47.34 & 47.78 & 49.39 & 50.83 & 51.28 & 3.9 \\
\hline & $\mathrm{HT}+\mathrm{Tx}$ & 49.01 & 50.21 & 52.06 & 53.56 & 54.17 & 5.2 \\
\hline \multirow{5}{*}{ Leeds } & HHD & 0.76 & 0.68 & 1.09 & 1.05 & 1.38 & 0.6 \\
\hline & $\mathrm{PD}$ & 6.98 & 6.41 & 5.09 & 4.42 & 3.99 & -3.0 \\
\hline & HT & 7.74 & 7.09 & 6.18 & 5.47 & 5.37 & -2.4 \\
\hline & $\mathrm{Tx}$ & 54.17 & 56.41 & 58.28 & 59.3 & 60.98 & 6.8 \\
\hline & $\mathrm{HT}+\mathrm{Tx}$ & 61.91 & 63.5 & 64.46 & 64.77 & 66.35 & 4.4 \\
\hline \multirow{5}{*}{ Leic } & HHD & 2.06 & 3.08 & 3.27 & 2.99 & 2.58 & 0.5 \\
\hline & $\mathrm{PD}$ & 7.82 & 7.6 & 6.92 & 5.44 & 4.8 & -3.0 \\
\hline & HT & 9.88 & 10.68 & 10.19 & 8.42 & 7.37 & -2.5 \\
\hline & $\mathrm{Tx}$ & 50.54 & 50.77 & 51.78 & 54.37 & 54.91 & 4.4 \\
\hline & $\mathrm{HT}+\mathrm{Tx}$ & 60.42 & 61.45 & 61.96 & 62.79 & 62.28 & 1.9 \\
\hline \multirow{5}{*}{ Liv Ain } & HHD & 2.91 & 3.12 & 2.82 & 3.78 & 4.1 & 1.2 \\
\hline & PD & 4.36 & 5.67 & 8.45 & 10.27 & 9.74 & 5.4 \\
\hline & HT & 7.27 & 8.78 & 11.27 & 14.05 & 13.85 & 6.6 \\
\hline & Tx & 42.73 & 43.34 & 47.61 & 45.14 & 43.85 & 1.1 \\
\hline & $\mathrm{HT}+\mathrm{Tx}$ & 50 & 52.12 & 58.87 & 59.19 & 57.69 & 7.7 \\
\hline \multirow{5}{*}{ Liv Roy } & HHD & 2.53 & 3.23 & 3.7 & 3.09 & 3.14 & 0.6 \\
\hline & PD & 7.7 & 7.26 & 6.51 & 6.4 & 7.01 & -0.7 \\
\hline & HT & 10.23 & 10.48 & 10.21 & 9.5 & 10.15 & -0.1 \\
\hline & $\mathrm{Tx}$ & 49.2 & 51.84 & 53.76 & 54.43 & 53.56 & 4.4 \\
\hline & $\mathrm{HT}+\mathrm{Tx}$ & 59.43 & 62.33 & 63.97 & 63.93 & 63.7 & 4.3 \\
\hline \multirow{5}{*}{ M RI } & HHD & 5.36 & 5.25 & 4.62 & 3.5 & 3.29 & -2.1 \\
\hline & $\mathrm{PD}$ & 7.87 & 6.83 & 6.45 & 5.6 & 4.86 & -3.0 \\
\hline & HT & 13.24 & 12.07 & 11.07 & 9.11 & 8.15 & -5.1 \\
\hline & $\mathrm{Tx}$ & 50.95 & 51.54 & 52.55 & 54.55 & 56.25 & 5.3 \\
\hline & $\mathrm{HT}+\mathrm{Tx}$ & 64.19 & 63.61 & 63.61 & 63.66 & 64.4 & 0.2 \\
\hline \multirow{5}{*}{ Middlbr } & HHD & 1.82 & 1.74 & 1.77 & 1.6 & 1.76 & -0.1 \\
\hline & $\mathrm{PD}$ & 2.21 & 1.25 & 1.53 & 1.26 & 2.41 & 0.2 \\
\hline & HT & 4.04 & 2.99 & 3.31 & 2.86 & 4.17 & 0.1 \\
\hline & $\mathrm{Tx}$ & 57.42 & 57.04 & 57.38 & 60.02 & 58.73 & 1.3 \\
\hline & $\mathrm{HT}+\mathrm{Tx}$ & 61.46 & 60.02 & 60.68 & 62.89 & 62.9 & 1.4 \\
\hline \multirow{5}{*}{ Newc } & HHD & 2.11 & 2.83 & 2.35 & 2.16 & 2.31 & 0.2 \\
\hline & PD & 5.5 & 5.32 & 4.7 & 5.62 & 4.83 & -0.7 \\
\hline & HT & 7.61 & 8.14 & 7.05 & 7.78 & 7.14 & -0.5 \\
\hline & $\mathrm{Tx}$ & 63.47 & 62.44 & 64.88 & 63.57 & 62.29 & -1.2 \\
\hline & $\mathrm{HT}+\mathrm{Tx}$ & 71.08 & 70.59 & 71.92 & 71.35 & 69.43 & -1.6 \\
\hline \multirow{5}{*}{ Newry } & HHD & 0.96 & 0.97 & 0.92 & 1.35 & 1.22 & 0.3 \\
\hline & $\mathrm{PD}$ & 5.77 & 7.73 & 8.29 & 7.21 & 8.98 & 3.2 \\
\hline & HT & 6.73 & 8.7 & 9.22 & 8.56 & 10.2 & 3.5 \\
\hline & $\mathrm{Tx}$ & 44.23 & 51.69 & 51.61 & 53.6 & 57.14 & 12.9 \\
\hline & $\mathrm{HT}+\mathrm{Tx}$ & 50.96 & 60.39 & 60.83 & 62.16 & 67.35 & 16.4 \\
\hline \multirow{5}{*}{ Norwch } & HHD & 2.81 & 3.23 & 3.7 & 3.95 & 3.24 & 0.4 \\
\hline & $\mathrm{PD}$ & 8.89 & 8.14 & 5.35 & 4.76 & 5.14 & -3.8 \\
\hline & HT & 11.7 & 11.37 & 9.05 & 8.71 & 8.38 & -3.3 \\
\hline & $\mathrm{Tx}$ & 43.37 & 43.16 & 49.66 & 51.16 & 49.32 & 6.0 \\
\hline & $\mathrm{HT}+\mathrm{Tx}$ & 55.07 & 54.53 & 58.71 & 59.86 & 57.7 & 2.6 \\
\hline
\end{tabular}


Table 13.7. Continued

\begin{tabular}{|c|c|c|c|c|c|c|c|}
\hline Centre & Modality & 2011 & 2012 & 2013 & 2014 & 2015 & $\begin{array}{c}\% \text { change } \\
5 \text { years }\end{array}$ \\
\hline \multirow{5}{*}{ Nottm } & HHD & 3.46 & 3.99 & 3.22 & 3.6 & 3.26 & -0.2 \\
\hline & $\mathrm{PD}$ & 10.27 & 9.38 & 8.63 & 8.63 & 8.1 & -2.2 \\
\hline & HT & 13.73 & 13.36 & 11.85 & 12.23 & 11.36 & -2.4 \\
\hline & $\mathrm{Tx}$ & 46.16 & 49.89 & 52.6 & 53.65 & 53.16 & 7.0 \\
\hline & $\mathrm{HT}+\mathrm{Tx}$ & 59.89 & 63.25 & 64.45 & 65.88 & 64.53 & 4.6 \\
\hline \multirow{5}{*}{ Oxford } & HHD & 1.02 & 1.13 & 1.53 & 0.97 & 1.01 & 0.0 \\
\hline & PD & 7.22 & 6.27 & 7.2 & 5.68 & 6.33 & -0.9 \\
\hline & HT & 8.24 & 7.41 & 8.73 & 6.65 & 7.34 & -0.9 \\
\hline & $\mathrm{Tx}$ & 60.36 & 62.06 & 61.67 & 62.6 & 64.38 & 4.0 \\
\hline & $\mathrm{HT}+\mathrm{Tx}$ & 68.6 & 69.46 & 70.4 & 69.25 & 71.72 & 3.1 \\
\hline \multirow{5}{*}{ Plymth } & HHD & 1.19 & 1.65 & 1.3 & 1.71 & 1.48 & 0.3 \\
\hline & PD & 10.71 & 8.25 & 7.78 & 7.26 & 7.38 & -3.3 \\
\hline & HT & 11.9 & 9.91 & 9.07 & 8.97 & 8.86 & -3.0 \\
\hline & $\mathrm{Tx}$ & 58.1 & 61.32 & 63.07 & 62.39 & 63.71 & 5.6 \\
\hline & $\mathrm{HT}+\mathrm{Tx}$ & 70 & 71.23 & 72.14 & 71.37 & 72.57 & 2.6 \\
\hline \multirow{5}{*}{ Ports } & HHD & 0.21 & 0.54 & 1.54 & 2.55 & 3.13 & 2.9 \\
\hline & PD & 6.66 & 5.63 & 5.44 & 4.91 & 4.26 & -2.4 \\
\hline & HT & 6.87 & 6.18 & 6.97 & 7.46 & 7.39 & 0.5 \\
\hline & $\mathrm{Tx}$ & 56.76 & 57.03 & 56.62 & 56.99 & 56.48 & -0.3 \\
\hline & $\mathrm{HT}+\mathrm{Tx}$ & 63.63 & 63.2 & 63.6 & 64.45 & 63.87 & 0.2 \\
\hline \multirow{5}{*}{ Prestn } & HHD & 3.05 & 3.31 & 2.87 & 2.92 & 3.03 & 0.0 \\
\hline & $\mathrm{PD}$ & 5.67 & 5.72 & 4.46 & 4.46 & 3.91 & -1.8 \\
\hline & HT & 8.72 & 9.03 & 7.33 & 7.38 & 6.94 & -1.8 \\
\hline & Tx & 49 & 49.88 & 51.79 & 52.34 & 53.69 & 4.7 \\
\hline & $\mathrm{HT}+\mathrm{Tx}$ & 57.72 & 58.91 & 59.12 & 59.72 & 60.64 & 2.9 \\
\hline \multirow{5}{*}{ Redng } & HHD & 0.86 & 1.45 & 1.37 & 1.42 & 1.07 & 0.2 \\
\hline & PD & 10.62 & 8.97 & 8.65 & 7.87 & 7.04 & -3.6 \\
\hline & HT & 11.48 & 10.42 & 10.01 & 9.29 & 8.11 & -3.4 \\
\hline & $\mathrm{Tx}$ & 54.94 & 57.45 & 58.7 & 59.67 & 60.19 & 5.3 \\
\hline & $\mathrm{HT}+\mathrm{Tx}$ & 66.42 & 67.88 & 68.71 & 68.96 & 68.3 & 1.9 \\
\hline \multirow{5}{*}{ Salford } & HHD & 1.91 & 2.07 & 2.43 & 1.84 & 1.56 & -0.4 \\
\hline & PD & 10.16 & 8.96 & 7.04 & 7.52 & 6.65 & -3.5 \\
\hline & HT & 12.07 & 11.02 & 9.46 & 9.36 & 8.22 & -3.9 \\
\hline & Tx & 57.17 & 58.31 & 60.13 & 59.04 & 61.82 & 4.7 \\
\hline & $\mathrm{HT}+\mathrm{Tx}$ & 69.24 & 69.34 & 69.6 & 68.4 & 70.03 & 0.8 \\
\hline \multirow{5}{*}{ Sheff } & HHD & 2.82 & 2.58 & 2.75 & 2.95 & 3.16 & 0.3 \\
\hline & PD & 5.3 & 5.66 & 5.66 & 4.94 & 4.78 & -0.5 \\
\hline & $\mathrm{HT}$ & 8.12 & 8.24 & 8.41 & 7.89 & 7.94 & -0.2 \\
\hline & $\mathrm{Tx}$ & 45.47 & 46.38 & 47.41 & 49.24 & 51.74 & 6.3 \\
\hline & $\mathrm{HT}+\mathrm{Tx}$ & 53.59 & 54.62 & 55.83 & 57.13 & 59.68 & 6.1 \\
\hline \multirow{5}{*}{ Shrew } & HHD & 3.02 & 4.41 & 5.04 & 4.39 & 6.33 & 3.3 \\
\hline & PD & 8.79 & 10.05 & 8.06 & 7.8 & 7.24 & -1.6 \\
\hline & HT & 11.81 & 14.46 & 13.1 & 12.2 & 13.57 & 1.8 \\
\hline & $\mathrm{Tx}$ & 43.72 & 41.67 & 44.08 & 44.39 & 45.7 & 2.0 \\
\hline & $\mathrm{HT}+\mathrm{Tx}$ & 55.53 & 56.13 & 57.18 & 56.59 & 59.28 & 3.8 \\
\hline \multirow{5}{*}{ Stevng } & HHD & 2.86 & 3.36 & 3.02 & 2.78 & 2.24 & -0.6 \\
\hline & PD & 3.3 & 3.36 & 4.24 & 2.42 & 1.56 & -1.7 \\
\hline & HT & 6.17 & 6.72 & 7.26 & 5.2 & 3.8 & -2.4 \\
\hline & $\mathrm{Tx}$ & 50.77 & 53.89 & 52.12 & 53.63 & 48.83 & -1.9 \\
\hline & $\mathrm{HT}+\mathrm{Tx}$ & 56.94 & 60.61 & 59.38 & 58.83 & 52.63 & -4.3 \\
\hline
\end{tabular}


Table 13.7. Continued

\begin{tabular}{|c|c|c|c|c|c|c|c|}
\hline Centre & Modality & 2011 & 2012 & 2013 & 2014 & 2015 & $\begin{array}{c}\% \text { change } \\
5 \text { years }\end{array}$ \\
\hline \multirow{5}{*}{ Sthend } & HHD & 1.15 & 1.14 & 0.7 & 0.33 & 0.99 & -0.2 \\
\hline & PD & 6.92 & 5.32 & 6.27 & 6.62 & 5.61 & -1.3 \\
\hline & HT & 8.08 & 6.46 & 6.97 & 6.95 & 6.6 & -1.5 \\
\hline & $\mathrm{Tx}$ & 46.92 & 49.81 & 51.92 & 54.97 & 52.48 & 5.6 \\
\hline & $\mathrm{HT}+\mathrm{Tx}$ & 55 & 56.27 & 58.89 & 61.92 & 59.08 & 4.1 \\
\hline \multirow{5}{*}{ Stoke } & HHD & 2.32 & 3.76 & 2.96 & 3.79 & 3.49 & 1.2 \\
\hline & $\mathrm{PD}$ & 11.17 & 11.28 & 11.2 & 10.13 & 8.9 & -2.3 \\
\hline & $\mathrm{HT}$ & 13.49 & 15.03 & 14.16 & 13.92 & 12.39 & -1.1 \\
\hline & $\mathrm{Tx}$ & 45.37 & 47.65 & 49.16 & 49.08 & 51.38 & 6.0 \\
\hline & $\mathrm{HT}+\mathrm{Tx}$ & 58.86 & 62.68 & 63.32 & 63 & 63.78 & 4.9 \\
\hline \multirow{5}{*}{ Sund } & HHD & 0.91 & 0.85 & 0.42 & 0.4 & 0.59 & -0.3 \\
\hline & $\mathrm{PD}$ & 4.08 & 4.65 & 2.54 & 3.63 & 3.55 & -0.5 \\
\hline & HT & 4.99 & 5.5 & 2.96 & 4.03 & 4.14 & -0.9 \\
\hline & $\mathrm{Tx}$ & 55.56 & 53.28 & 55.81 & 54.03 & 52.66 & -2.9 \\
\hline & $\mathrm{HT}+\mathrm{Tx}$ & 60.54 & 58.77 & 58.77 & 58.06 & 56.8 & -3.7 \\
\hline \multirow{5}{*}{ Swanse } & HHD & 3.32 & 3.36 & 2.38 & 4.61 & 4.05 & 0.7 \\
\hline & PD & 7.13 & 8.46 & 6.89 & 6.26 & 6.98 & -0.1 \\
\hline & HT & 10.44 & 11.82 & 9.26 & 10.87 & 11.04 & 0.6 \\
\hline & $\mathrm{Tx}$ & 48.77 & 50.5 & 54.04 & 54.37 & 51.91 & 3.1 \\
\hline & $\mathrm{HT}+\mathrm{Tx}$ & 59.21 & 62.31 & 63.3 & 65.25 & 62.95 & 3.7 \\
\hline \multirow{5}{*}{ Truro } & HHD & 0.29 & 1.36 & 1.92 & 2.42 & 2.43 & 2.1 \\
\hline & PD & 7.47 & 6.23 & 6.59 & 5.65 & 5.35 & -2.1 \\
\hline & HT & 7.76 & 7.59 & 8.52 & 8.06 & 7.79 & 0.0 \\
\hline & $\mathrm{Tx}$ & 49.14 & 52.03 & 52.47 & 54.57 & 55.47 & 6.3 \\
\hline & $\mathrm{HT}+\mathrm{Tx}$ & 56.9 & 59.62 & 60.99 & 62.63 & 63.26 & 6.4 \\
\hline \multirow{5}{*}{ Ulster } & HHD & 1.91 & 2.28 & 2.22 & 2.2 & 1.21 & -0.7 \\
\hline & PD & 1.44 & 3.2 & 2.67 & 1.76 & 2.43 & 1.0 \\
\hline & HT & 3.35 & 5.48 & 4.89 & 3.96 & 3.64 & 0.3 \\
\hline & $\mathrm{Tx}$ & 48.8 & 47.95 & 50.67 & 54.63 & 53.85 & 5.1 \\
\hline & $\mathrm{HT}+\mathrm{Tx}$ & 52.15 & 53.42 & 55.56 & 58.59 & 57.49 & 5.3 \\
\hline \multirow{5}{*}{ West NI } & HHD & 1.39 & 2.2 & 2.17 & 1.31 & 1.23 & -0.2 \\
\hline & $\mathrm{PD}$ & 6.62 & 6.96 & 5.42 & 4.59 & 3.7 & -2.9 \\
\hline & HT & 8.01 & 9.16 & 7.58 & 5.9 & 4.94 & -3.1 \\
\hline & $\mathrm{Tx}$ & 42.51 & 45.05 & 54.15 & 58.03 & 59.57 & 17.1 \\
\hline & $\mathrm{HT}+\mathrm{Tx}$ & 50.52 & 54.21 & 61.73 & 63.93 & 64.51 & 14.0 \\
\hline \multirow{5}{*}{ Wirral } & HHD & 0.23 & 0.93 & 2.38 & 1.76 & 2.98 & 2.8 \\
\hline & $\mathrm{PD}$ & 9.51 & 7.42 & 7.58 & 4.85 & 4.36 & -5.2 \\
\hline & HT & 9.74 & 8.35 & 9.96 & 6.61 & 7.34 & -2.4 \\
\hline & $\mathrm{Tx}$ & 46.4 & 47.8 & 47.19 & 50 & 52.52 & 6.1 \\
\hline & $\mathrm{HT}+\mathrm{Tx}$ & 56.15 & 56.15 & 57.14 & 56.61 & 59.86 & 3.7 \\
\hline \multirow{5}{*}{ Wolve } & HHD & 2.58 & 3.21 & 3.12 & 3.62 & 4.05 & 1.5 \\
\hline & $\mathrm{PD}$ & 11.43 & 14.1 & 12.46 & 11.43 & 11.43 & 0.0 \\
\hline & HT & 14.01 & 17.31 & 15.58 & 15.05 & 15.48 & 1.5 \\
\hline & $\mathrm{Tx}$ & 38.49 & 39.1 & 41.84 & 42.4 & 41.82 & 3.3 \\
\hline & $\mathrm{HT}+\mathrm{Tx}$ & 52.5 & 56.41 & 57.42 & 57.45 & 57.31 & 4.8 \\
\hline \multirow{5}{*}{ Wrexm } & HHD & 0.43 & 0.41 & 0.79 & 0.36 & 1.38 & 1.0 \\
\hline & $\mathrm{PD}$ & 8.7 & 9.13 & 8.66 & 10.71 & 12.8 & 4.1 \\
\hline & HT & 9.13 & 9.54 & 9.45 & 11.07 & 14.19 & 5.1 \\
\hline & $\mathrm{Tx}$ & 53.04 & 51.04 & 51.57 & 48.93 & 48.79 & -4.3 \\
\hline & $\mathrm{HT}+\mathrm{Tx}$ & 62.17 & 60.58 & 61.02 & 60 & 62.98 & 0.8 \\
\hline
\end{tabular}


Table 13.7. Continued

\begin{tabular}{llrrrrrr}
\hline \multirow{2}{*}{ Centre } & & & & & & \multicolumn{2}{c}{ \% change } \\
5 years
\end{tabular}

HHD - home haemodialysis; PD - peritoneal dialysis; HT - home therapy; Tx - transplant ${ }^{a}$ Based on postcode of residency

${ }^{\mathrm{b}}$ Cambridge was unable to submit patient level data for 2015 in time 

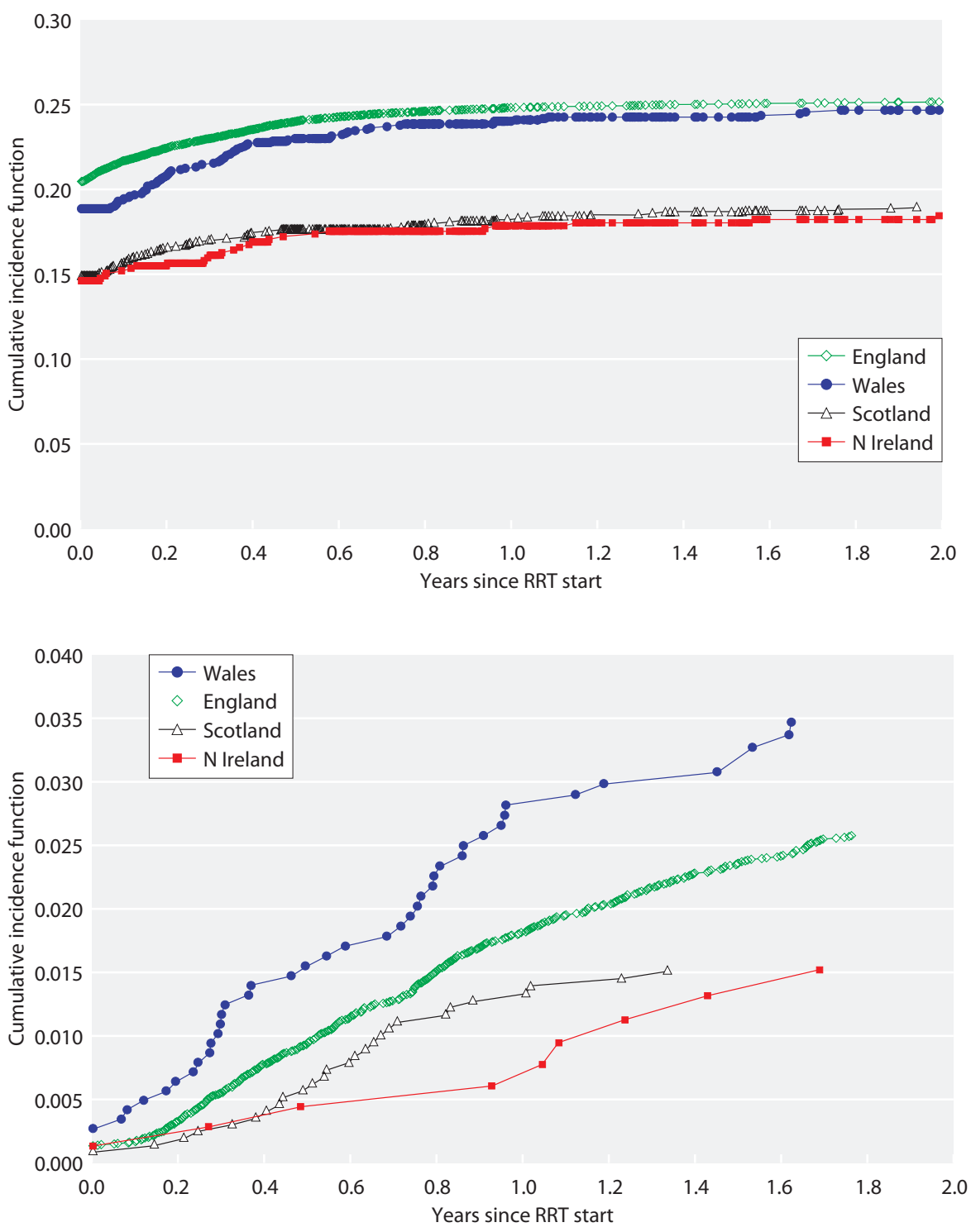

Fig. 13.18. Cumulative probability of starting PD since commencing RRT, by country, in the incident cohort 2011-2014, censoring at transplantation
Fig. 13.19. Cumulative probability of starting HHD since commencing RRT, by country, in the incident cohort 2011-2014, censoring at transplantation 
